OPEN ACCESS

Edited by:

Keith Elkon,

University of Washington,

United States

Reviewed by:

Tomas Mikael Mustelin,

University of Washington,

United States

Marko Radic,

University of Tennessee College of

Medicine, United States

*Correspondence:

Caroline Grönwall

caroline.gronwall@ki.se

tThese authors share first authorship

Specialty section:

This article was submitted to

Autoimmune and Autoinflammatory

Disorders,

a section of the journal

Frontiers in Immunology

Received: 19 September 2018 Accepted: 07 December 2018

Published: 04 January 2019

Citation:

Lloyd KA, Wigerblad G, Sahlström P Garimella MG, Chemin K, Steen J, Titcombe PJ, Marklein B, Zhou D, Stålesen R, Ossipova $E$, Lundqvist $C$

Ekwall O, Rönnelid J, Mueller DL, Karlsson MCl, Kaplan MJ, Skriner K Klareskog L, Wermeling F, Malmström V and Grönwall C (2019) Differential ACPA Binding to Nuclear Antigens Reveals a PAD-Independent

Pathway and a Distinct Subset of Acetylation Cross-Reactive

Autoantibodies in Rheumatoid Arthritis. Front. Immunol. 9:3033. doi: 10.3389/fimmu.2018.03033

\section{Differential ACPA Binding to Nuclear Antigens Reveals a PAD-Independent Pathway and a Distinct Subset of Acetylation Cross-Reactive Autoantibodies in Rheumatoid Arthritis}

\author{
Katy A. Lloyd ${ }^{1 \dagger}$, Gustaf Wigerblad ${ }^{1,2 \dagger}$, Peter Sahlström ${ }^{1,3}$, Manasa G. Garimella ${ }^{4}$, \\ Karine Chemin ${ }^{1}$, Johanna Steen ${ }^{1}$, Philip J. Titcombe ${ }^{1,5}$, Bianka Marklein ${ }^{2}$, Diana Zhou ${ }^{1}$, \\ Ragnhild Stålesen ${ }^{1}$, Elena Ossipova ${ }^{1}$, Christina Lundqvist ${ }^{6}$, Olov Ekwall ${ }^{6,7}$, \\ Johan Rönnelid ${ }^{8}$, Daniel L. Mueller ${ }^{5}$, Mikael C. I. Karlsson ${ }^{4}$, Mariana J. Kaplan'2, \\ Karl Skriner ${ }^{3}$, Lars Klareskog ${ }^{1}$, Fredrik Wermeling ${ }^{1}$, Vivianne Malmström ${ }^{1}$ and \\ Caroline Grönwall ${ }^{1 *}$ \\ ${ }^{1}$ Center for Molecular Medicine, Division of Rheumatology, Department of Medicine, Karolinska Institutet, Karolinska \\ University Hospital, Stockholm, Sweden, ${ }^{2}$ Systemic Autoimmunity Branch, Intramural Research Program, National \\ Institute of Arthritis and Musculoskeletal and Skin Diseases, National Institutes of Health, Bethesda, MD, United States, \\ ${ }^{3}$ Department of Medicine, Charité University Hospital, Berlin, Germany, ${ }^{4}$ Department of Microbiology, Tumor and Cell biology, \\ Karolinska Institutet, Stockholm, Sweden, ${ }^{5}$ The Center for Immunology, University of Minnesota Medical School, \\ Minneapolis, MN, United States, ${ }^{6}$ Department of Rheumatology and Inflammation Research, Institute of Medicine, \\ Sahlgrenska Academy, University of Gothenburg, Gothenburg, Sweden, ${ }^{7}$ Department of Pediatrics, Institute of Clinical \\ Sciences, Sahlgrenska Academy, University of Gothenburg, Gothenburg, Sweden, ${ }^{8}$ Department of Immunology, Genetics \\ and Pathology, Uppsala University, Uppsala, Sweden
}

Rheumatoid arthritis (RA) associated anti-citrullinated protein autoantibodies (ACPA) target a wide range of modified proteins. Citrullination occurs during physiological processes such as apoptosis, yet little is known about the interaction of ACPA with nuclear antigens or apoptotic cells. Since uncleared apoptotic cells and neutrophil extracellular trap (NET) products have been postulated to be central sources of autoantigen and immunostimulation in autoimmune disease, we sought to characterize the anti-nuclear and anti-neutrophil reactivities of ACPA. Serology showed that a subset of anti-CCP2 seropositive RA patients had high reactivity to full-length citrullinated histones. In contrast, seronegative RA patients displayed elevated IgG reactivity to native histone compared to controls, but no citrulline-specific reactivity. Screening of 10 single B-cell derived monoclonal ACPA from RA patients revealed that four ACPA exhibited strong binding to apoptotic cells and three of these had anti-nuclear (ANA) autoantibody reactivity. Modified histones were confirmed to be the primary targets of this anti-nuclear ACPA subset following immunoprecipitation from apoptotic cell lysates. Monoclonal ACPA were also screened for reactivities against stimulated murine and human neutrophils, and all the nuclear-reactive monoclonal ACPA bound to NETs. Intriguingly, one ACPA mAb displayed a contrasting cytoplasmic perinuclear neutrophil binding and may represent a different NET-reactive ACPA subset. Notably, 
studies of CRISPR-Cas9 PAD4 KO cells and cells from PAD KO mice showed that the cytoplasmic NET-binding was fully dependent on PAD4, whilst nuclear- and histone-mediated NET reactivity was largely PAD-independent. Our further analysis revealed that the nuclear binding could be explained by consensus-motif driven ACPA cross-reactivity to acetylated histones. Specific acetylated histone peptides targeted by the monoclonal antibodies were identified and the anti-modified protein autoantibody (AMPA) profile of the ACPA was found to correlate with the functional activity of the antibodies. In conclusion, when investigating monoclonal ACPA, we could group ACPA into distinct subsets based on their nuclear binding-patterns and acetylation-mediated binding to apoptotic cells, neutrophils, and NETs. Differential anti-modified protein reactivities of RA-autoantibody subsets could have an important functional impact and provide insights in RA pathogenesis.

Keywords: anti-citrullinated protein autoantibodies, acetylation, rheumatoid arthritis, anti-CCP, PAD4, apoptosis, neutrophil extracellular traps (NETs), ANA

\section{INTRODUCTION}

In rheumatoid arthritis (RA), the production of anti-citrullinated protein autoantibodies (ACPA) is a distinct disease feature which is used for classification of seropositive RA, and where presence of ACPA associates with increased disease severity and worse prognosis [reviewed in (1)]. Recent studies suggest that ACPA may directly play an active role in RA pathogenesis, as ACPA have been shown to mediate bone loss, pain, and enhance arthritis in vivo (2-6), as well as inducing pro-inflammatory events in different in vitro cell systems (3, 4, 7-11). Citrullination involves the post-translational modification of arginine residues to citrulline by a family of enzymes referred to as peptidylarginine deiminases (PAD), which are involved in several physiological processes including gene regulation, cell differentiation, and apoptosis (12). Of particular interest for RA, citrullination associated with PAD2 and PAD4 expression is present in different inflammatory processes, and is also found in the inflamed RA synovium $(13,14)$. PAD-mediated citrullination of nuclear antigens such as histones has previously been reported to play an essential role in the unique form of cell death known as neutrophil extracellular trap formation (NETosis) $(15,16)$, and it has been postulated that enhanced NET production could provide an important source of autoantigens within the inflamed joints of RA patients (7).

In the clinic, the presence of ACPA IgG in the serum of RA patients can be captured using synthetic cyclic citrullinated peptide (CCP2/CCP3) assays. However, serum ACPA IgG can react with peptides derived from many different citrullinated proteins including $\alpha$-enolase, filaggrin, vimentin, fibrinogen, and histones (17-21). When evaluating the fine-specificity of monoclonal ACPA derived from memory B cells and plasma cells from RA patients it was recently shown that individual ACPA mAbs display remarkable cross-reactivity to different citrullinated peptides and proteins $(5,10,11,22,23)$. Hence, ACPA mAbs bind to consensus citrulline motifs in peptides rather than specific proteins, albeit with different clones exhibiting distinct peptide reactivity profiles $(5,10)$. Despite these studies, it is still unclear which citrullinated targets may mediate the pathogenic effects of these cross-reactive ACPA and to which extent monoclonal ACPA displaying different fine-specificity profiles are able to mediate distinct functional effects.

The majority of monoclonal ACPA investigated to date are reported to be encoded by highly somatic hypermutated Ig variable genes $(5,10,11,24,25)$ and display hypermutation driven variable region glycosylation (25-27), which together are two features that represent the most prominent ACPA characteristics. Since ACPA are present before clinical arthritis and synovitis (28-30), it seems plausible that the process of somatic mutation and selection of certain ACPA-positive B cells progresses over during a long time before onset of arthritis. It is therefore imperative to understand more of which targets and specific BCR features that are most critical in the selection of the autoreactive B cells, in the early phase of autoimmunity, as well as in the pathogenic escalation to chronic disease.

Nuclear antigens generated during cell death have previously been implicated in autoimmune and inflammatory diseases. These autoantigens are postulated to be exposed either due to impaired efferocytosis of apoptotic cells or increased activation of neutrophils with resulting NETosis. Herein, we investigate the interaction between monoclonal ACPA and nuclear antigens, in order to contribute to the understanding of the triggering mechanisms of the autoreactivity and pathogenic roles of different ACPA. Our results highlight a novel interaction between ACPA and apoptotic cells that overlaps with NET-binding. We identify a distinct subset of ACPA with an anti-modified protein autoantibody (AMPA) profile which drive these interactions and demonstrate that the recognition of the nuclear targets of these cross-reactive ACPA were selectively due to binding to specific acetylated histone epitopes.

\section{METHODS}

\section{Clinical Samples}

Serum samples were obtained from 243 RA patients and 157 population-based controls from the Epidemiological Investigation of Rheumatoid Arthritis (EIRA) study (31). All 
patients fulfilled the 1987 ACR RA classification criteria (32) and were subgrouped as ACPA seropositive (193 subjects) or seronegative (50 subjects) using the anti-CCP2 assay (CCPlus, Euro Diagnostica). Patient samples have previously been screened for anti-citrullinated peptide fine-specificities with an antigen microarray multiplex assay, based on Phadia's ImmunoCAP ISAC system, as previously described (33). Peripheral blood mononuclear cells (PBMC) for in vitro assays were isolated from heparinized blood from healthy volunteers. The local ethics committee at Karolinska University Hospital approved the study, and all the experiments were performed according to good clinical practice and good laboratory practice. All study subjects gave informed consent to participate.

\section{Detection of Antibodies to Citrullinated and Native Histone 2B in RA Serum}

Serum levels of autoantibodies to citrullinated and native fulllength histone were measured by ELISA in patients and controls. Since histone $2 \mathrm{~B}$ amino acid sequence is conserved between species, purified bovine protein was used in the assay. Briefly, 2 $\mathrm{mg} / \mathrm{ml}$ histone $2 \mathrm{~B}$ (His $2 \mathrm{~B}$, Immunovision) was citrullinated in solution for $2 \mathrm{~h}$ at $37^{\circ} \mathrm{C}$ in $100 \mathrm{mM}$ Tris, $10 \mathrm{mM} \mathrm{CaCl}_{2}, 5 \mathrm{mM}$ DTT, PAD4 $0.75 \mathrm{U} / \mathrm{mg}$ histone protein (Calbiochem). Native His2B was prepared using the same protocol but without the PAD enzyme. Antigens were then buffer exchanged to PBS using slide-a-lyzer dialysis cassettes (Life Technologies). Citrullinated or native His2B were coated at $3 \mu \mathrm{g} / \mathrm{ml}$ in $100 \mathrm{mM}$ carbonate buffer ( $\mathrm{pH}$ 9.6) into separate wells on the same ELISA plate (using Corning high binding ELISA plates), and subsequently blocked with 3\% BSA (Sigma-Aldrich) in PBS. Serum samples were evaluated at 1:50 dilution in sample buffer (2\% BSA, 5\% normal donkey sera (Jackson Immunoresearch), 0.1\% Tween20, and $0.3 \mathrm{M} \mathrm{NaCl}$ in PBS). Reactivity was detected with goat $\mathrm{F}(\mathrm{ab})_{2}$ anti-human $\operatorname{IgG}(\mathrm{Fc})-\mathrm{HRP}$ in PBS (Jackson Immunoresearch), developed with TMB substrate (Biolegend), and stopped with $2 \mathrm{~N}$ $\mathrm{H}_{2} \mathrm{SO}_{4}$. An RA reference sample was used as a positive control on the cit-His2B surface to generate a standard curve and extrapolate reactivity values in relative units $(\mathrm{RU}) / \mathrm{ml}$. Cutoff for positivity was set based on 95th percentile on the population controls for anti-native His2B, anti-citrullinated His2B, or normalized reactivity [IgG anti-cit-His2B ( $\mathrm{RU} / \mathrm{ml})$ divided by IgG anti-natHis2B (RU/ml)].

\section{ACPA Monoclonal Antibodies}

ACPA and control mAbs were derived from single B cells from different $B$ cell populations isolated from RA patients, as previously reported $(5,10,26,34-36)$. Four monoclonal ACPA were derived from synovial plasma cells (1325:01B09, 1325:04C03, 1325:05C06, 1325:07E07) (10). Six ACPA were derived from antigen-tetramer sorted circulating memory B cells, using cyclic citrullinated alpha enolase peptide (CEP) tetramers (clones 37CEPT1G09, 37CEPT2C04), or cyclic citrullinated filaggrin peptide 1 (CFC1) tetramers (clones 14CFCT2D09, 14CFCT2H12, 14CFCT3G09, 62CFCT1E04) (5). RA synovial memory B cell-derived mAbs with no identified specific binding, were used as negative controls (1362:01E02, 1276:01G09). Immunoglobulin genes were cloned using established methods
$(35,37)$ and expressed as human IgG1 or chimeric murine IgG2a in Expi293 cells (Life Technologies). Additionally, 1325:01B09 was mutated to generate a heavy chain with null-binding to $\mathrm{Fc} \gamma$ receptors following a previously reported strategy with validated G236R and L328R amino acid replacements (GRLR hIgG1, template plasmid was a kind gift from Dr. Stylianos Bournazos and Dr. Jeffrey V. Ravetch, Rockefeller University) (38). Quality control of the expressed IgG included SDS-PAGE, size exclusion chromatography aggregation tests, endotoxin test, and citrullinated antigen-specificity ELISA. hIgG1 mAbs were conjugated with DyLight 650 (Thermo Fisher Scientific) for flow cytometry analysis of citrullination in murine neutrophils, and biotinylated with EZ-Link Sulfo-NHS-LC-Biotin (Thermo Fisher) for human thymus immunofluorescence, according to manufacturer's instructions.

\section{Screening of Monoclonal ACPA Binding to Citrullinated Full-Length Proteins}

Human recombinant histones $(1,3$, and 4), hnRNPs (A3, B1, $\mathrm{D}, \mathrm{DL})$, and vimentin were expressed and purified as previously described (39). Antigens solubilized in $8 \mathrm{M}$ urea were coated on Nunc Maxisorb 96-well plates. Plates were blocked with 5\% milk powder in PBS, and washed with PBS/0.1\% Tween. Plate-bound antigens were citrullinated using $150 \mathrm{mU} / \mathrm{ml}$ PAD2 or PAD4 (Modiquest) in buffer (50 mM Tris, $10 \mathrm{mM} \mathrm{CaCl}_{2}, 1 \mathrm{mM}$ DTT). Binding of monoclonal ACPA $(1 \mu \mathrm{g} / \mathrm{ml})$ to different citrullinated antigens were determined with anti-hIgG Fc-HRP (SigmaAldrich) and developed with TMB (Seramun Diagnostica).

\section{Monoclonal ACPA Binding to Modified Peptides}

ACPA mAb reactivity to the citrulline (cit) peptides cit-Vim60-75 (biotin-HQCVYAT-Cit-SSAV-Cit-L-Cit-SSVPC), Cit-Fib $\alpha 563-$ 583 (biotin-HQCHHPGIAEFPS-Cit-GKSSSYSKQFC), or acetyl-lysine (Ac) peptides Ac-His2B:6-22 (biotinHQCSAPAPK-Ac-GSKKAVTKAQC), Ac-His4:1-23 (biotinSGRG-Ac-GG-Ac-GLG-Ac-GGA-Ac-RHRKVLR) or native arginine (Nat-Vim60-75 and Nat-Fiba563-583) or lysine (NatHis2B:6-22 and Nat-His4:1-23) counterparts was detected by ELISA. Briefly, high-binding half-area ELISA plates were coated with neutravidin $3 \mu \mathrm{g} / \mathrm{ml}$ (Life Technologies), blocked with $3 \%$ BSA, and biotinylated peptides were captured at $1 \mu \mathrm{g} / \mathrm{ml}$ followed by incubation with human mAbs at $5 \mu \mathrm{g} / \mathrm{ml}$ in sample buffer (2\% BSA, 5\% normal donkey sera (Jackson Immunoresearch), $0.1 \%$ Tween 20 , and $0.3 \mathrm{M} \mathrm{NaCl}$ in $\mathrm{PBS}$ ). Reactivity was detected with goat $\mathrm{F}(\mathrm{ab})_{2}$ anti-human $\operatorname{IgG}(\mathrm{Fc})$ HRP in PBS (Jackson Immunoresearch) and TMB substrate (Biolegend).

\section{Detecting ACPA Binding to Apoptotic Cells}

Murine thymocytes were isolated from thymus tissue, strained through a $70 \mu \mathrm{M}$ cell strainer, and re-suspended to $2 \times 10^{6}$ cells/ml in RPMI 1640 with 10\% ultra-low IgG FBS (Life Technologies), 1\% penicillin/streptomycin and 1\% L-glutamine (Life Technologies). Apoptosis was induced by incubation with $10 \mu \mathrm{M}$ dexamethasone (Sigma-Aldrich) at $37^{\circ} \mathrm{C}$ for $4 \mathrm{~h}$, as previously described (40). In Jurkat (human T-cell line) cells, 
apoptosis was induced with $100 \mathrm{ng} / \mathrm{ml}$ anti-CD95/Fas (EOS9.1, Biolegend) for $2 \mathrm{~h}$ or $25 \mu \mathrm{M}$ etoposide (Sigma-Aldrich) overnight at $37^{\circ} \mathrm{C}$. Thereafter, cells were incubated with $\mathrm{mAbs}(10 \mu \mathrm{g} / \mathrm{ml})$ in $3 \%$ BSA in PBS for $1 \mathrm{~h}$ on ice, and detected with biotinylated goat anti-human IgG (Jackson Immunoresearch) and streptavidinPE (BD Biosciences). Apoptosis was confirmed by staining cells with Annexin $\mathrm{V}$ and 7AAD (BD Biosciences) according to the manufacturer's instructions. Data were acquired using a BD FACSVerse ${ }^{\mathrm{TM}}$ flow cytometer and analyzed with FlowJo software (Tristar). For PAD or HDAC inhibition, Jurkats were pre-incubated with either $20 \mu \mathrm{M} \mathrm{Cl}$-amidine (Cl-A, Calbiochem) or $100 \mathrm{ng} / \mathrm{ml}$ trichostatin A (TSA, Sigma-Aldrich), respectively, for $3 \mathrm{~h}$ at $37^{\circ} \mathrm{C}$ before stimulation of apoptosis with $25 \mu \mathrm{M}$ etoposide (Sigma-Aldrich) overnight. Whole cell lysates were prepared in RIPA buffer (Sigma-Aldrich) with Complete protease inhibitor cocktail (Roche) and then $20 \mu \mathrm{g}$ protein per lane was separated on SDS-PAGE under reducing conditions using NuPAGE bis-tris gels (4-12\%) and MES-SDS running buffer (Life Technologies) followed by transfer to PVDF membranes according to the manufacturer's instructions (Life Technologies). ACPA binding was detected in the Western blot with $5 \mu \mathrm{g} / \mathrm{ml}$ hIgG1 followed by rabbit anti-human $\operatorname{IgG}(\mathrm{Fc})-\mathrm{HRP}$ in PBS (Jackson Immunoresearch) and chemiluminescence developing with Clarity Western ECL substrate (Bio-Rad). Acetylation of histone 2B was detected with rabbit anti-AcH2B-K12 (Cell Signaling) and anti-rabbit-HRP (Cell Signaling). Citrullination in cell lysates was detected using a rhodamine based citrullinespecific probe (Cayman Chemicals). The probe was solubilized in acetonitrile:water $(2: 1)$ and $3 \mu \mathrm{g}$ probe were added to 40 $\mu \mathrm{L}$ cell lysates pre-treated with $20 \%$ trichloroacetic acid (at 1 $\mathrm{mg} / \mathrm{ml}$ total protein). Samples were incubated $30 \mathrm{~min}$ followed by centrifugation at $15,000 \mathrm{~g}$ for $5 \mathrm{~min}$. Pellets were washed twice in ice-cold acetone and resuspended in LDS loading dye with reducing agent and SDS-PAGE separated. In-gel fluorescence in the gels was visualized with the ChemiDoc MP system (Bio-Rad). To validate protein loading, the gels were subsequently stained with Coomassie (SimplyBlue SafeStain, Life Technologies).

\section{Immunoprecipitation of Apoptotic Cell Antigens}

Immunoprecipitations were used to detect ACPA-binding proteins in apoptotic cells. Apoptosis was induced in Jurkat cells with $25 \mu \mathrm{M}$ etoposide (Sigma-Aldrich) for $16 \mathrm{~h}$ at $37^{\circ} \mathrm{C}$. Cells were washed with PBS and resuspended $\left(1 \times 10^{7} / \mathrm{ml}\right)$ in TNI lysis buffer (50 mM Tris, $250 \mathrm{mM} \mathrm{NaCl,} \mathrm{0.5 \%} \mathrm{Igepal} \mathrm{CA-}$ 630) supplemented with Complete protease inhibitor cocktail (Roche), and incubated for $30 \mathrm{~min}$ on ice. After centrifugation, the lysate soluble phases were pre-cleared by $1 \mathrm{~h}$ incubation with protein $G$ resin (GE Healthcare), followed by addition of $3 \mu \mathrm{g}$ ACPA or control hIgG1 to $400 \mu \mathrm{l}$ lysate, and incubation at $4{ }^{\circ} \mathrm{C}$ overnight. Antibody-antigen complexes were captured with $40 \mu \mathrm{l}$ protein G resin, washed twice with TNI including detergent and without detergent, and either eluted with four times $50 \mu \mathrm{l} 0.5 \mathrm{M}$ ammonium hydroxide and dehydration by SpeedVac or separated on SDS-PAGE under reducing conditions using NuPAGE bis-tris gels and MES-SDS running buffer (Life
Technologies). SimplyBlue SafeStain (Life Technologies) stained bands were excised and subjected to mass spectrometry analysis.

\section{In-gel Digestion and LC-MS/MS Analysis}

Excised gel bands were destained in $100 \mathrm{mM}$ ammonium bicarbonate at $37^{\circ} \mathrm{C}$ for $30 \mathrm{~min}$. In-gel digestion was performed as previously described (41). Peptides were extracted from the gel bands using subsequently $20 \%$ acetonitrile (ACN) in $0.1 \%$ formic acid (FA), 50\% ACN in $0.1 \% \mathrm{FA}$, and $100 \%$ ACN. Collected supernatants were dried using SpeedVac and reconstituted in 3\% $\mathrm{ACN}$ in $0.1 \% \mathrm{FA}$.

Peptide identification was performed using Dionex Ultimate 3,000 nano-LC system coupled via electrospray ion source (Thermo Fisher Scientific) to a Q-Exactive Orbitrap (Thermo Fisher Scientific). Peptides were trapped onto Acclaim ${ }^{\mathrm{TM}}$ PepMap $^{\text {TM }} 100 \mathrm{C} 18,3 \mu \mathrm{m}, 100 \AA$ Årap column, $75 \mu \mathrm{m}$ i.d. $\times 2 \mathrm{~cm}$, and separated on nanoEase $\mathrm{M} / \mathrm{Z}^{\mathrm{TM}}$ HSS T3, $100 \AA, 1.8 \mu \mathrm{m}$, $75 \mu \mathrm{m} \times 250 \mathrm{~mm}$ column (Waters). Peptides were eluted with a linear gradient of $5-45 \%$ of buffer B (95\% v/v acetonitrile, $0.1 \% \mathrm{v} / \mathrm{v} \mathrm{FA}$ ) at flow rate $250 \mathrm{nl} / \mathrm{min}$ at $\mathrm{RT}$. Data acquisition was performed with a Top10 data-dependent MS/MS scan. Scan range was set to $300-1,600 \mathrm{~m} / \mathrm{z}$, with a maximum injection time of $250 \mathrm{~ms}$ and resolution of 70,000 at $\mathrm{m} / \mathrm{z} 400$. Fragmentation of precursor ions was performed at $28 \mathrm{eV}$ of collision energy. MS/MS scans were performed at resolution of 17,500 with an ion target value of $2 \times 10^{5}$ and the injection time of $200 \mathrm{~ms}$. MS raw files were analyzed by MaxQuant software (Version 1.5.5.1) (42) and searched against human Uniprot/Swissprot database (release-2018_04), with enzyme specificity set to "Trypsin" allowing two missed cleaved sites. Carbamidomethylation was set as fixed modifications and deamidation of $\mathrm{R}, \mathrm{Q}$, and $\mathrm{N}$ set as variable modifications. Precursor mass deviation was set to 10 ppm and fragment mass deviation to $20 \mathrm{ppm}$. The false discovery rate was set to 0.01 .

\section{Solid-Phase Immune Complex Assay}

Monoclonal ACPA were used to generate plate-bound CitHis2B immune complexes, as previously described with minor modifications (43). Briefly, $10 \mu \mathrm{g} / \mathrm{ml}$ PAD4-citrullinated His2B or control native histone proteins were coated to MaxiSorp ELISA plates (Nunc) overnight at $4^{\circ} \mathrm{C}$. Plates were blocked with $1 \%$ ultra-low IgG FBS in PBS, then incubated with monoclonal antibodies $(10 \mu \mathrm{g} / \mathrm{ml})$ for $1 \mathrm{~h}$ at $37^{\circ} \mathrm{C}$. PBMC were isolated from healthy donors with Ficoll-Paque Plus (GE Healthcare) separation and added to the wells $\left(10^{6}\right.$ cells/ $\left.\mathrm{ml}\right)$ in RPMI 1640 medium with $5 \%$ ultra-low IgG FBS, $1 \%$ penicillin/streptomycin, $1 \%$ HEPES, and $12.5 \mu \mathrm{g} / \mathrm{ml}$ polymyxin B sulfate (Sigma-Aldrich). TNF- $\alpha$ or IL- 8 release in supernatants after $20 \mathrm{~h}$ was measured by ELISA (Biolegend), using recombinant IL- 8 or TNF- $\alpha$ as standards (Biolegend).

\section{Investigation of ANA Reactivity}

Monoclonal ACPA $(5 \mu \mathrm{g} / \mathrm{ml})$ and patient sera (1:40 dilution) were screened for anti-nuclear autoantibody reactivities (ANA) using the NOVA ${ }^{\circledR}$ Lite HEp-2 ANA substrate slide kit, according to the manufacturer's guidelines (Inova Diagnostics). Staining patterns were designated based on the guidelines provided by 
the International Consensus on Antinuclear Antibody Pattern (ICAP) available at the website www.anapatterns.org (44). ACPA mAbs were also assayed at $5 \mu \mathrm{g} / \mathrm{ml}$ with ANA line blot (EUROLINE ANA profile 3, Euroimmune).

\section{ACPA Binding to Human Thymus}

Thymus tissue was obtained from children undergoing cardiac surgery. Parents gave informed written consent. The study was approved by the Regional Ethical Board at the University of Gothenburg. The tissue was embedded in Optimal cutting temperature compound (OCT) (Histolab Products AB) in isopentane pre-cooled with liquid nitrogen, and $7 \mu \mathrm{m}$ sections were cut and fixed in cold acetone. After rehydration in PBS and blocking with Protein Block (Dako), tissue sections were stained with biotinylated monoclonal antibodies $(5 \mu \mathrm{g} / \mathrm{ml})$ and anti-cytokeratin 5 (BioLegend), and detected with antirabbit-AlexaFluor488, streptavidin-AlexaFluor555, and Hoechst, and mounted with ProLong Gold Antifade mountant (all Life Technologies). For flow cytometry, thymocyte single cell suspensions were prepared by enzymatic (DNase I and Liberase $\mathrm{TH}$, Roche) and mechanical (gentleMACS ${ }^{\mathrm{TM}}$ Dissociator, Miltenyi Biotec) treatment. Cells were blocked with Beriglobin (CSL Behring) and stained with biotinylated monoclonal antibodies $(10 \mu \mathrm{g} / \mathrm{ml}$ ) and Fixable Viability Dye 506 (Life Technologies), followed by Streptavidin APC (BD Bioscience). For intracellular staining, cells were fixed with the Transcription Factor Staining Buffer Set (Life Technologies).

\section{ACPA Binding to Human Neutrophils and NETs}

Enriched human neutrophil fractions were isolated from heparinized blood from two healthy donors, as previously described (45). Briefly, after Ficoll-Paque separation (GE Healthcare), granulocytes were twice treated with red blood cell lysis using ACK lysing buffer (Thermo Fisher Scientific). Primary human neutrophils $\left(0.2 \times 10^{6}\right)$ were cultured in Hanks' balanced salt solution without calcium/magnesium for $4 \mathrm{~h}$ on $6 \mathrm{~mm}$ coverslips coated with $0.02 \%$ poly-L-Lysine (Sigma-Aldrich). Neutrophils were left untreated (medium) or stimulated with ionomycin $(1 \mu \mathrm{M}$, Calbiochem) or phorbol 12-myristate 13acetate (PMA) $(50 \mathrm{nM}$, Calbiochem), then fixed with 3.7\% formaldehyde and incubated in PBS-glycine $(10 \mathrm{mM})$. Cells were permeabilized (eBioscience, Foxp3 permeabilization buffer), stained with murine chimeric ACPA IgG2a or control mAbs $(10 \mu \mathrm{g} / \mathrm{ml})$, and subsequently with anti-mouse-AlexaFluor488 (Invitrogen) and Hoechst (Thermo Fisher Scientific). Coverslips were mounted onto glass slides using Fluoromount-G (Southern Biotech). Images were acquired using a Leica TCS SP5 and a 63x oil objective. A z-dimension series was taken every $0.2 \mu \mathrm{m}$. Images were analyzed with the Fiji software.

\section{ACPA Binding to Murine Neutrophils and NETs}

ECoM-G cells (kind gift from Dr. Mark Kamps, University of California San Diego) (46) were grown in DMEM with $10 \%$ FBS (Life Technologies), 4\% GM-CSF conditioned medium, 1\% penicillin/streptomycin/L-glutamine (Life Technologies), and
$1 \mu \mathrm{M} \beta$-estradiol (Sigma Aldrich). To differentiate cells into neutrophils, the $\beta$-estradiol was removed and cells were cultured for 5 days until further analysis. Cells were stimulated with ionomycin for $4 \mathrm{~h}(1 \mu \mathrm{M}$, Thermo Fisher Scientific) or a DMSO vehicle for NETosis induction. Ionomycin produced enhanced NET formation compared to PMA in this cell system. Pharmacological inhibition of PAD enzymes was performed by addition of $100 \mu \mathrm{M} \mathrm{Cl}$-amidine (Cl-A, Calbiochem) during the 5 day differentiation culture. For intracellular staining, cells were fixed and permeabilized using Foxp3 buffer set according to manufacturer's instructions (Thermo Fisher Scientific), stained with $10 \mu \mathrm{g} / \mathrm{ml}$ with DyLight-650-conjugated ACPA hIgG1 or control monoclonal antibody, and co-stained with anti-Ly6/G. Flow cytometry data was acquired using a BD Accuri instrument (BD Biosciences). For immunohistochemistry, ECoM-G cells were grown on coverslips (Falcon, Corning), fixed using $4 \%$ PFA, permeabilized ( $0.2 \%$ TritonX), and stained with ACPA $(10 \mu \mathrm{g} / \mathrm{ml})$, followed by detection with Alexa-488 goat antihuman IgG (Life technologies), and DAPI. Images were acquired as above. Guide RNA (gRNA) targeting the Padi4 gene (CTGGACAAGTCTAACCCGGT) was selected using the Green listed software (47) and the Brie library (48), and were cloned into the vector px459 (kind gift from Dr. Feng Zhang, Addgene plasmid \#62988) (49). ECoM-G cells were electroporated (Neon System, Life Technologies) with the plasmid and rested for $24 \mathrm{~h}$ prior to puromycin selection $(10 \mu \mathrm{g} / \mathrm{ml})$ for $48 \mathrm{~h}$. Limiting dilution were then used to generate single cells in 96-well plates, which were sequenced to determine successful mutation of the PADI4 gene. Loss of protein was validated using separation of cell extracts on SDS-PAGE (NuPage 4-12\% Bis Tris, Life Technologies), transfer to PVDF membrane (Bio-Rad Trans Blot Turbo), and detection with an anti-PAD4 specific antibody (ab214810, Abcam) with anti- $\beta$-actin as loading control. For staining of primary bone marrow cells, tibial bone marrow was isolated from 8-12-week-old female Balb/c, FVB, Pad2 ${ }^{-/-}$, or Pad4 ${ }^{-/-}$mice, strained through a $70 \mu \mathrm{M}$ cell strainer, and stained with biotinylated lineage panel (Miltenyi Biotech) or CD11b (Cell Signaling) and Ly6G (Cell Signaling), in addition to $10 \mu \mathrm{g} / \mathrm{ml}$ DyLight-650-conjugated hIgG1 ACPA. Bone marrow from WT FVB, Pad2 ${ }^{-/-}$, or Pad4 ${ }^{-/-}$mice was purified using magnetic beads (neutrophil isolation kit, Miltenyi Biotec) according to manufacturer's instructions. One million purified neutrophils were resuspended in DMEM with $1 \mu \mathrm{M}$ ionomycin or vehicle for $1 \mathrm{~h}$, then processed for analysis. Detection of citrullinated proteins in cell lysates using a rhodamine based citrulline-specific probe (Cayman Chemicals) was performed as described above.

\section{In vivo Administration of Apoptotic Cells}

For generating apoptotic cells, thymocytes from 4- to 5-wk-old sex-matched C57BL/6 mice were cultured for $6 \mathrm{~h}$ in complete RPMI 1640 media (Life Technologies) plus $1 \mu \mathrm{M}$ dexamethasone (Sigma-Aldrich) at $37^{\circ} \mathrm{C}$, as described previously (50). Mice were injected i.v. with $10 \times 10^{6}$ apoptotic cells weekly for 4 weeks. The mice received murine chimeric IgG2a ACPA, $1 \mathrm{mg}$ per mouse, together with apoptotic cells in the first and third injections. Apoptotic cells were pre-incubated with ACPA mAbs $(5 \mathrm{mg} / \mathrm{ml})$ 


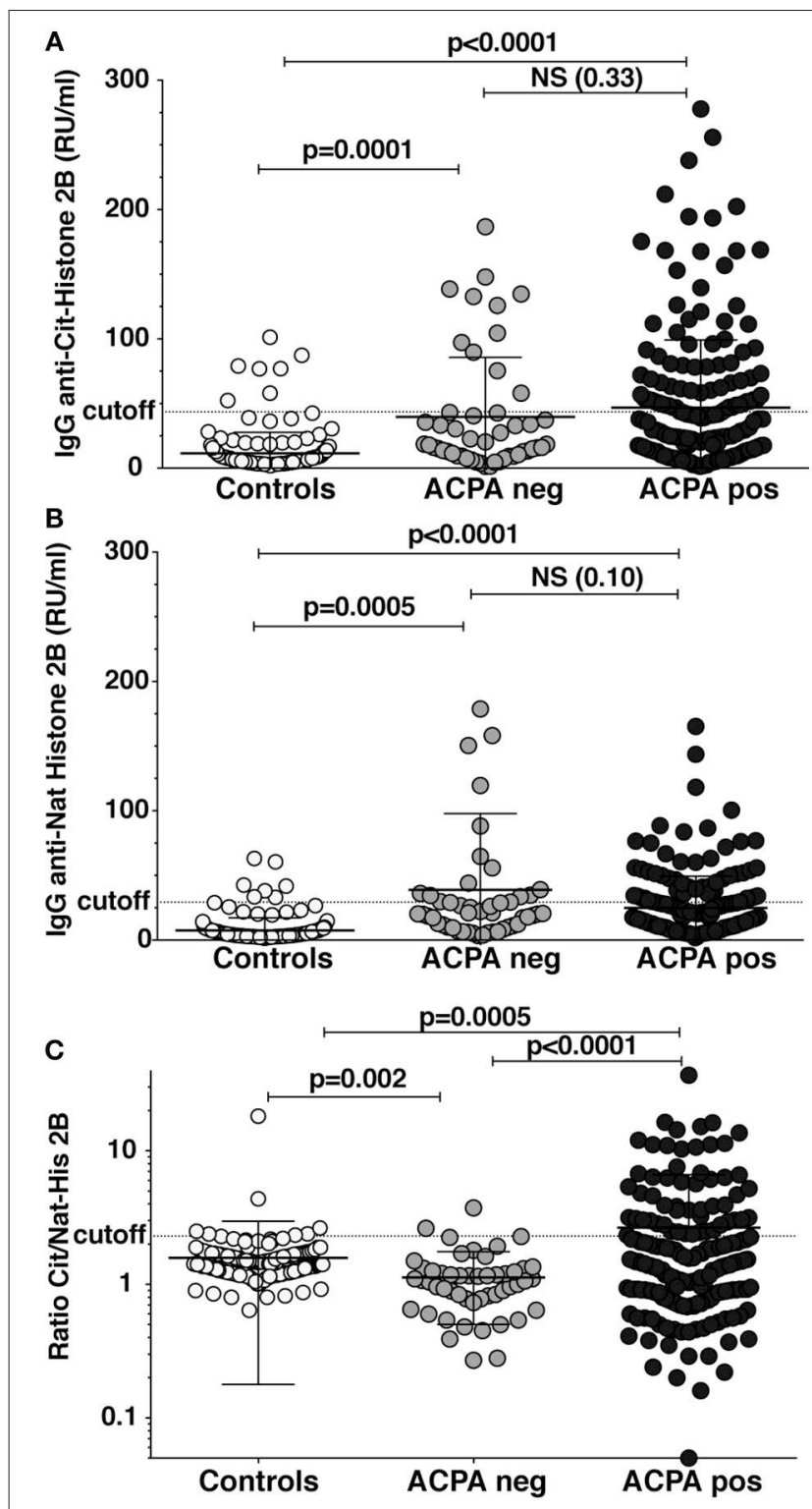

FIGURE 1 | Reactivity against citrullinated full-length histone in RA patients. Serum levels of IgG binding to full-length citrullinated histone (A) and native histone (B) was determined by ELISA in 193 CCP2 positive RA patients, 50 CCP2 negative, and 157 healthy population controls using purified bovine histone 2B citrullinated in solution with PAD4. (C) The IgG anti-citrullinated histone $2 \mathrm{~B}$ was normalized for native histone reactivity in the patients (Ratio Cit/Nat-His2B). Cutoff for positivity highlighted in the figure was determined by the 95th percentile of the population controls. $P$-values are presented from t-test with Welch correction.

for $30 \mathrm{~min}$ before the injections. Four group of mice were investigated, receiving: PBS and no apoptotic cells; only apoptotic cells, apoptotic cells in combination with the ACPA 1325:01B09 and apoptotic cells in combination with the ACPA 1325:04C03. Mice were bled every week and serum was collected. Antibodies against DNA were measured as described previously (50). Briefly, ELISA plates were coated with methylated BSA plus calf thymus
DNA (Sigma-Aldrich). Antigen-reactive IgG in the serum was measured with alkaline phosphate-conjugated anti-mouse IgG antibody (Southern Biotech). Antibodies against Ro-52, Ro60, SmD1, and SS-B were measured using commercial kits (Signosis, Inc), following manufacturer's instructions. Reactivity to citrullinated full-length proteins were assessed by ELISA, as injected IgG2a antibodies could be discriminated from endogenously produced IgG2 owing to the C57BL/6 IgG2c restriction. Briefly, rabbit PAD citrullinated recombinant human vimentin (produced in-house), PAD4 citrullinated purified human fibrinogen (Sigma Aldrich), or PAD4 citrullinated histone 2B were coated at $3 \mu \mathrm{g} / \mathrm{ml}$, wells were blocked with $3 \%$ BSA and reactivity was assessed in serum at 1:100 dilution. HRP conjugated subclass specific detection antibodies (Southern Biotech) were used to measure either the injected antibodies (anti-IgG2a) or the induced response (anti-IgG1, anti-IgG2c). Anti-CCP3 reactivity was determined using commercial ELISA plates (Inova Diagnostics) but with the murine subclass specific detection reagents as above.

\section{Statistical Analysis}

Statistical analysis of serological data was performed with Prism (Graphpad Softwares). Serological measurements were found to have a non-Gaussian distribution and unequal variances. Hence, $t$-test with Welch correction for unequal standard deviation was used for comparing continuous variables between groups and Spearman analysis for correlation analysis. Experimental data points from in vitro assays were compared with Student's $t$-test. $P$ $<0.05$ were considered significant.

\section{RESULTS}

\section{Reactivities to Native and Citrullinated Histones in RA Patients}

Autoantibodies to full-length native and citrullinated histone (His2B) were investigated using sera from ACPA-positive and ACPA-negative RA patients and population controls. As shown in Figure 1, we found increased levels of antibodies to both native and citrullinated His2B protein in both ACPA-negative and ACPA-positive patients as compared to controls. However, only the ACPA-positive patients had citrulline-specific reactivity, which was evident when adjusting the citrulline reactivity against native reactivity (ratio anti-cit/natHis2B). Significantly raised IgG cit-His2B/nat-His2B serum reactivities were seen in the ACPA-positive patients compared to ACPA-negative patients ( $p$ $<0.0001$ ) or controls ( $p=0.0005$ ) (Figure 1C). Overall, 29\% of ACPA-positive patients were positive for reactivities against citrullinated His2B after normalization for anti-native His2B (Table 1). Any detectable reactivity in the citrullinated histone assay among ACPA negative patients could be explained by reactivity to native histone epitopes, something that could also be visualized when analyzing the correlation between native and citrulline reactivities (Supplementary Figure 1). It is also possible that there are reactivities to cit-His epitopes that are not captured by the CCP2 test, similar to what has been seen for some other citrulline fine-specificities (17). One of the population controls, although without RA diagnosis, was found to have 
TABLE 1 | lgG reactivities to full-length citrullinated histone 2B in rheumatoid arthritis patients.

\begin{tabular}{|c|c|c|c|c|c|c|}
\hline & \multirow{2}{*}{$\begin{array}{c}\begin{array}{c}\text { Population controls } \\
(n=157)\end{array} \\
\text { Frequency/mean }\end{array}$} & \multicolumn{2}{|c|}{ ACPA negative RA $(n=50)$} & \multicolumn{2}{|c|}{ ACPA positive RA $(n=193)$} & \multirow{2}{*}{$\begin{array}{c}\text { ACPA pos vs. } \\
\text { ACPA neg RA } \\
\text { p-value\# }\end{array}$} \\
\hline & & Frequency/mean & $p$-value\# & Frequency/mean & $p$-value\# & \\
\hline Age & $55.4 \pm 10.5$ & $51.1 \pm 13.6$ & 0.04 & $49.9 \pm 11.8$ & $<0.0001$ & NS (0.58) \\
\hline Females & $71 \%(111 / 157)$ & $60 \%(30 / 50)$ & NS $(0.16)$ & $75 \%(145 / 193)$ & NS $(0.40)$ & NS $(0.051)$ \\
\hline DAS28 & N/A & $5.3 \pm 1.1(27)$ & N/A & $4.9 \pm 1.4(123)$ & N/A & NS (0.12) \\
\hline CRP & N/A & $22.7 \pm 22.3(31)$ & $\mathrm{N} / \mathrm{A}$ & $28.1 \pm 31.0(132)$ & $\mathrm{N} / \mathrm{A}$ & NS (0.27) \\
\hline $\begin{array}{l}\text { IgG anti-Cit His2B (RU/ml) } \\
\text { mean } \pm \mathrm{SD}\end{array}$ & $11.6 \pm 16.1$ & $39.6 \pm 46.1$ & 0.0001 & $46.9 \pm 52.2$ & $<0.0001$ & NS (0.33) \\
\hline $\begin{array}{l}\text { Positive IgG anti-Cit His2B } \\
(>43.5 \mathrm{RU} / \mathrm{ml}) \%(\mathrm{n} / \mathrm{N}) €\end{array}$ & $4.5 \%(7 / 157)$ & $22 \%(11 / 50)$ & 0.0005 & $37 \%(72 / 193)$ & $<0.0001$ & 0.046 \\
\hline $\begin{array}{l}\text { IgG anti-native His2B (RU/ml) } \\
\text { mean } \pm \mathrm{SD}\end{array}$ & $7.8 \pm 9.7$ & $38.9 \pm 59.0$ & 0.0005 & $24.8 \pm 24.7$ & $<0.0001$ & NS $(0.10)$ \\
\hline $\begin{array}{l}\text { Positive lgG anti-native His2B } \\
(>29.3 \mathrm{RU} / \mathrm{ml}) \%(\mathrm{n} / \mathrm{N}) €\end{array}$ & $4.5 \%(7 / 157)$ & $32 \%(16 / 50)$ & $<0.0001$ & $28 \%(55 / 193)$ & $<0.0001$ & NS (0.61) \\
\hline $\begin{array}{l}\text { Normalized IgG anti-cit-His2B/nat-His2B } \\
\text { mean } \pm \text { SD }\end{array}$ & $1.58 \pm 1.4$ & $1.13 \pm 0.62$ & 0.002 & $2.66 \pm 3.96$ & 0.0005 & $<0.0001$ \\
\hline $\begin{array}{l}\text { Positive IgG anti cit-His2B/nat-His2B } \\
(>2.3) \%(n / N) €\end{array}$ & $4.5 \%(7 / 157)$ & $4 \%(2 / 50)$ & NS (1) & 29\% (55/193) & $<0.0001$ & 0.0001 \\
\hline
\end{tabular}

$€$ Cutoff was set based on 95th percentile on the population controls.

\# $P$-value from 2-sided $t$-test with Welch's correction for difference in variance.

Ratio cit/native ACPA positive RA, sensitivity 49\%, specificity 89\%, OR 7.6 (3.4-17.2)//compared to controls//.

Ratio cit/native ACPA positive RA, sensitivity 24\%, specificity 96\% OR 8.5 (2.0-36.2)//compared to ACPA negative//.

high anti-CCP2 levels that explained the observed anti-cit-His2B reactivity in this individual. The higher levels of reactivity to native histone observed in ACPA-negative patients compared to controls were reflected by a significantly lower anti-cit/natHis $2 \mathrm{~B}$ ratio ( $p=0.002$, Figure $1 \mathrm{C})$. IgG anti-cit-His2B levels showed a significant negative correlation with age in RA ( $p$ $=0.03, r=-0.14)$ and positive correlation with IgG antiCCP2 levels ( $p<0.0001, r=0.3$; Supplementary Table 1). No significant associations with CRP levels or DAS28 disease activity score were observed neither for $\operatorname{IgG}$ anti-cit-His2B levels, nor for anti-cit/nat normalized values. When comparing fine specificities, anti-cit-His2B and the anti-cit/nat-His2B ratio correlated with citrullinated vimentin $(p<0.001)$, fibrinogen $(p<0.0001)$, and $\alpha$-enolase (CEP-1, $p<0.0001)$ peptides (Supplementary Table 1).

\section{A Subset of Monoclonal ACPA Have a Binding Profile With High Reactivity to Citrullinated Nuclear Antigens}

Among potential nuclear autoantigens, histones, and heterogeneous nuclear ribonucleoproteins (hnRNPs) have been implicated in RA. We therefore investigated the reactivity of 10 RA patient-derived monoclonal ACPA toward full-length citrullinated histones compared to citrullinated hnRNPs. Some ACPA (1325:01B09, 37CEPT2C04, 37CEPT1G09) exhibited broad reactivities for different citrullinated histones and citrullinated hnRNPs (Figure 2), whereas other ACPA bound more to hnRNPs compared to histones (1325:05C06, 14CFCT3G09, 1325:04C03), and one group did not bind any of the investigated antigens. The majority of the monoclonal ACPA were highly specific for citrullinated compared to native proteins and only two clones (37CEPT2C04 and 37CEPT1G09) exhibited a limited cross-reactivity to the native forms of certain full-length antigens (Figure 2). The monoclonal ACPA all displayed anti-CCP2 and anti-CCP3 reactivity at $1,000 \mathrm{ng} / \mathrm{ml}$ using commercial assays and the majority also had high reactivity at $100 \mathrm{ng} / \mathrm{ml}$ (Supplementary Figure 2), as well as specific reactivity to different citrullinated peptides and no/limited reactivity to arginine peptide versions determined by several antigen microarray platforms as previously published (5, 10, 33). Monoclonal ACPA also bound to the full-length citrullinated cytoplasmic proteins vimentin and $\alpha$-enolase (Supplementary Figure 3). When comparing the antigens sideby-side, the citrullinated histone ACPA binding strength was equivalent to binding to citrullinated fibrinogen and citrullinated vimentin, and among the different clones the highest cit-histone binding was detected for 1325:01B09 with significant reactivity below $100 \mathrm{ng} / \mathrm{ml}$ (Supplementary Figure 4). In general, the clones with high cit-vimentin and cit- $\alpha$-enolase reactivities showed reduced reactivity to multiple citrullinated histones. No major differences in ACPA reactivities could be detected due to the preference of proteins citrullinated by either PAD2 or PAD4 (Figure 2). In addition, the results were not dependent on which citrullination protocol was used as similar binding was detected with on-plate citrullination compared to in-solution citrullination (Supplementary Figure 4).

\section{Citrullinated Histone-Containing Immune Complexes Stimulate Innate Immune Responses in vitro}

Immune complex mediated immune cell activation may play a role in the RA pathogenesis and citrullinated histones have been suggested to be important drivers, hence, we investigated the ability of the monoclonal ACPA in citrullinated His2B immune 

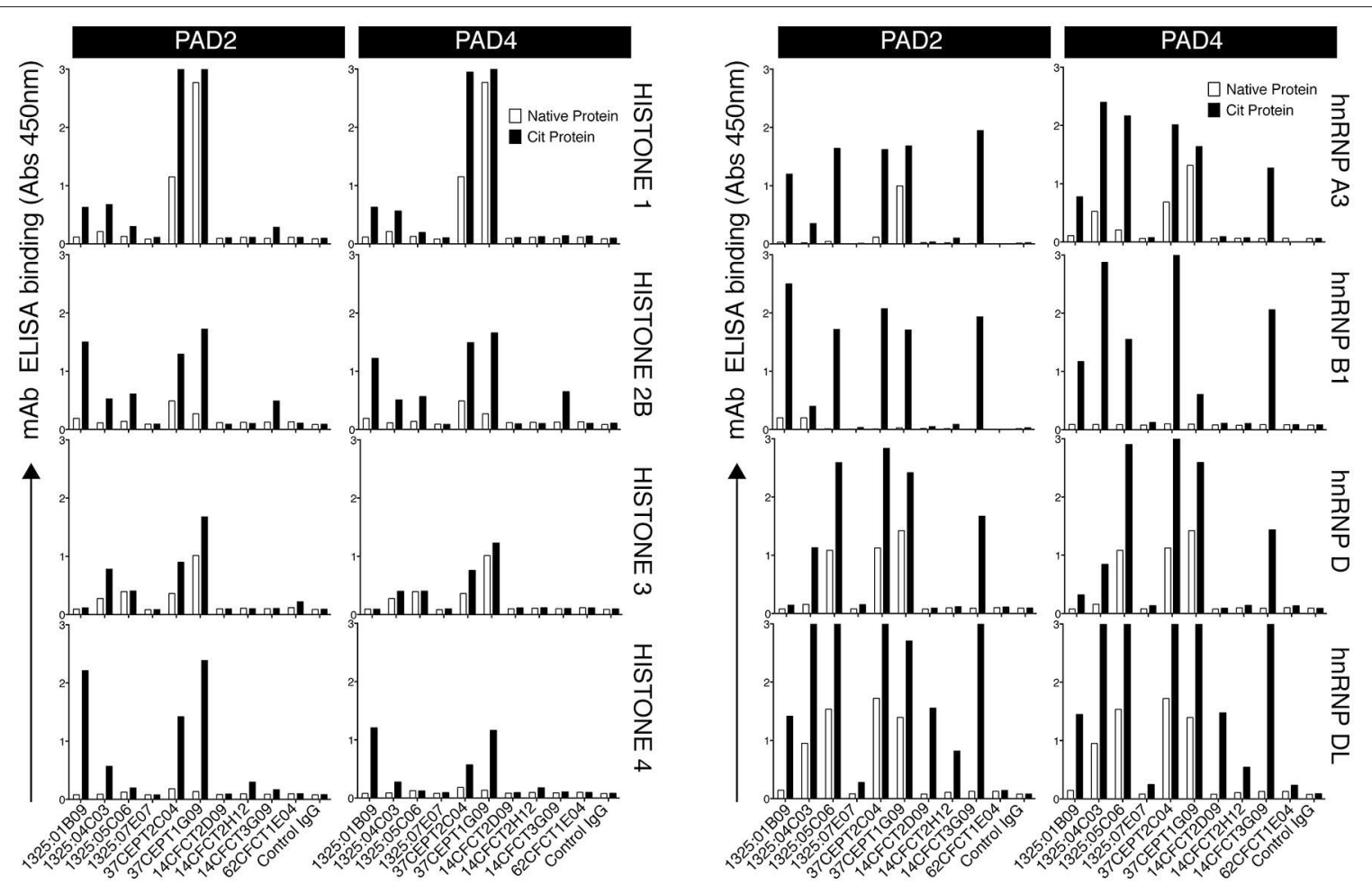

FIGURE 2 | A subset of monoclonal ACPA-lgG exhibit reactivities to citrullinated nuclear antigens. Reactivity of 10 monoclonal ACPA IgG to full-length citrullinated nuclear antigens was evaluated by ELISA using recombinant human antigens (hnRNP A3, hnRNP B1, hnRNP D, hnRNP DL, Histone 1, Histone 3, Histone 4) or purified antigen (Histone 2B) citrullinated on-plate in solid phase under denaturing conditions with either PAD2 or PAD4. Native protein was mock-treated without the enzyme. Human lgG1 was evaluated for binding at $5 \mu \mathrm{g} / \mathrm{ml}$. The RA-derived mAb 1276:01G09 was used as negative control (control lgG). The figure shows representative data of at least three repeated experiments and bars depicts average value of duplicates.

complexes to induce pro-inflammatory cytokine secretions. For this, freshly isolated but otherwise unstimulated PBMCs were incubated on either native or citrullinated His2B preincubated with ACPA hIgG1 mAbs. Interestingly, only one of the citrullinated His2B-binding ACPA (1325:01B09) induced a significant increase in IL- 8 and TNF- $\alpha(p<0.0001$, Figure 3 and Supplementary Figure 5). This activity reflected the 1325:01B09 cit-histone 2B binding level and was dependent on Fc $\gamma$-receptor interactions, as a mutated version of 1325:01B09 (GRLR) unable to bind $\mathrm{Fc} \gamma \mathrm{R}$ failed to induce cytokine production (Figure 3). No significant cytokine release was introduced by citrullinated histone antigen alone or by any of the monoclonal ACPA themselves.

\section{ACPA Bind to Apoptotic Cells and Have ANA Activity}

Since apoptosis has been implicated in the triggering of autoimmunity and pathogenesis of autoimmune diseases, and is associated with increased citrullination of histones, we investigated whether monoclonal ACPA exhibited reactivities for apoptotic cells. A subset of the monoclonal ACPA (1325:01B09, 37CEPT2C04, 37CEPT1G09, 1325:05C06) was observed to bind both human and murine apoptotic cells by flow cytometry (Figures 4A,B respectively). Importantly, these clones previously demonstrated high binding to different citrullinated nuclear antigens by ELISA. There was no difference in binding to murine or human cells, or by apoptosis induction using different agents (dexamethosone, anti-Fas, or etoposide). In all cases, ACPA predominantly bound late apoptotic cells, with partial binding to early apoptotic cells, and no reactivity against healthy cells. Interestingly, co-incubation with the PAD-inhibitor Clamidine (Cl-A) during apoptosis did not affect the ACPA apoptotic cell binding, indicating either that the modified antigens are pre-formed, or that the binding is PAD-independent (Supplementary Figure 6).

Immunoblotting revealed that these ACPA bound strongest to proteins with molecular weights of $\sim 17$ and $\sim 14 \mathrm{kDa}$ in apoptotic cell lysates (Figure 4C). Immunoprecipitations of apoptotic Jurkat lysate with apoptotic cell-reactive ACPA (1325:01B09, 37CEPT2C04, 37CEPT1G09, 1325:05C06) showed capture of four proteins $(13-14,17-18,18-20$, and 36-37 $\mathrm{kDa}$ ). Such binding was absent for control IgG or when using apoptotic cell-reactive ACPA together with lysate from untreated cells (Figure 4D). The clones 1325:01B09, 37CEPT2C04, 37CEPT1G09 showed the strongest binding, whereas 1325:05C06 showed considerably weaker co-precipitation. This clone also had less reactivity in the previous Western blot staining. Mass spectrometry analysis of the precipitated proteins identified histone 4 , histone $2 \mathrm{~A}$, histone $2 \mathrm{~B} / 3$, and histone 1 , respectively. The $36-37 \mathrm{kDa}$ band contained multiple proteins including 

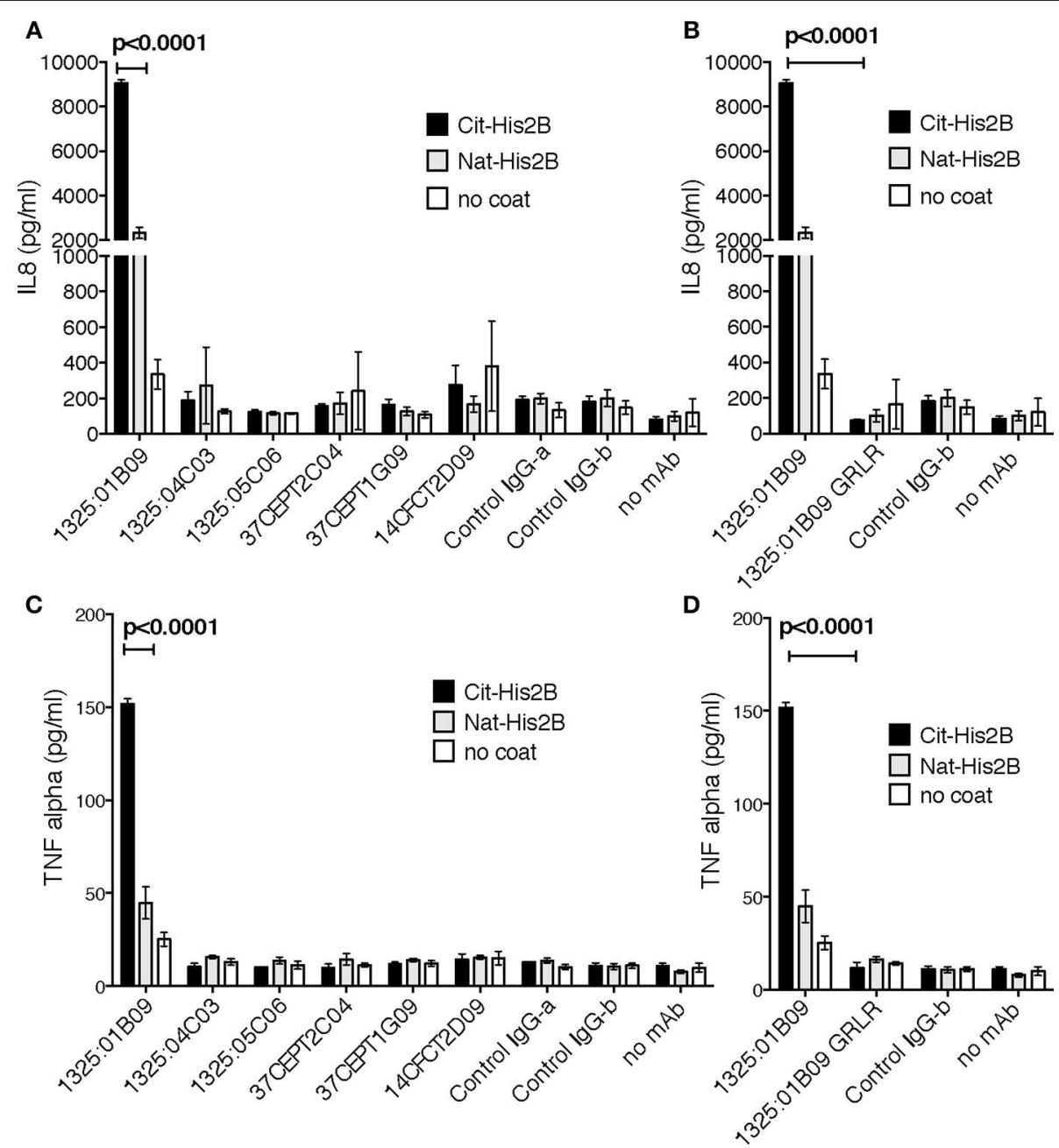

FIGURE 3 | The interaction between citrullinated histone and monoclonal ACPA induce innate responses. The immune stimulatory effect of seven ACPA monoclonal with high cit-histone 2B binding (1325:01B09, 37CEPT1G09, 37CEPT2C04), medium binding (1325:04C03, 1325:05C06, 14CFCT3G09), and no or low binding (14CFCT2D09) was evaluated using plate-bound immune complexes at $10 \mu \mathrm{g} / \mathrm{ml}$ with PAD4 citrullinated histone 2B. Healthy donor PBMC were incubated with the antigen-captured IgG plates for $20 \mathrm{~h}$ at $37^{\circ} \mathrm{C}$ and IL-8 (A) and TNF- $\alpha$ (C) expression was subsequently assessed in the cell supernatants by ELISA. The importance of FC $\gamma$ R interaction for 1325:01B09-mediated cytokine stimulations was assessed by comparison to the Fc $\gamma$ R-null binding genetic variant 1325:01B09 GRLR (B,D).

Both recombinant RA derived human IgG (1276:01G09, Control lgG-b) and commercial isotype control lgG (ET901, Biolegend, Control lgG-a) were used as controls.

The figure show values in triplicate for one representative donor. Data for multiple donors are available in Supplementary Figure 5. $P$-values are derived from student $t$-test.

actin. Furthermore, SDS-PAGE of the whole cell lysates before immunoprecipitations showed higher level of free histone protein in the apoptotic cell lysates than in the lysate from control treated cells (Supplementary Figure 7).

To further characterize ACPA binding to nuclear antigen using conventional serologic methods, we screened the ACPA for anti-nuclear antibody (ANA) HEp-2 cell staining. Only a subset of the ACPA (1325:01B09, 37CEPT2C04, 37CEPT1G09) were positive for ANA staining (Figure 5A). They produced a nuclear staining pattern most closely similar to the dense fine speckled or AC-2 pattern according to the ICAP ANA nomenclature, with heterogeneity in brightness and distribution of speckles and the characteristic coarse speckled stained metaphase plate (Figure 5A). Notably, the ANA positive
ACPA did not significantly bind to any purified native ANA autoantigens including histone, dsDNA, or DFS70 by line blot ANA profile screening. A weak binding to nucleosomes disappeared when mAb 37CEPT2C04 was diluted, while total IgG-binding remained; this was regarded as non-specific binding (Supplementary Figures 8B,C). Furthermore, the ACPA did not bind to dsDNA in ELISA using the methylated-BSA dsDNA capture protocol. If instead citrullinated histone coated wells were used, the ACPA-cit-His binding was completely blocked, and hence no binding was detected to histone-dsDNA complexes (Supplementary Figure 8A). We screen a limited number of ACPA-positive and ACPA-negative RA patient sera for HEp-2 ANA. The results show that there were no correlations between ANA patterns and neither ACPA positivity nor anti-histone 


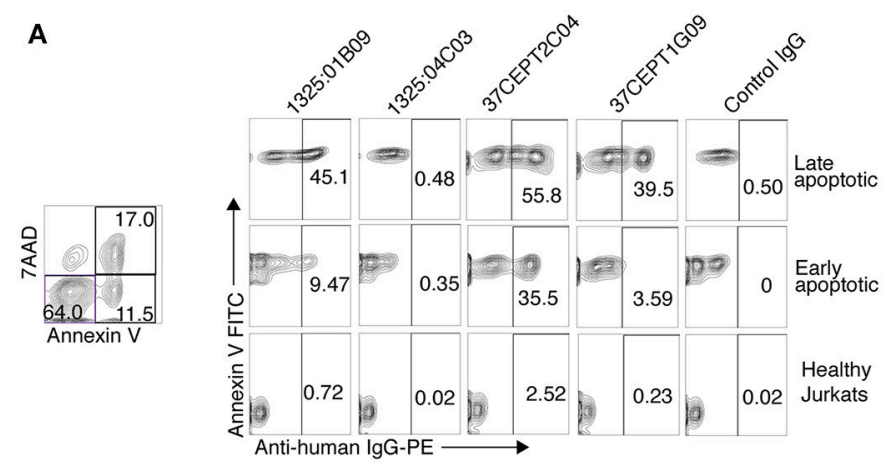

C

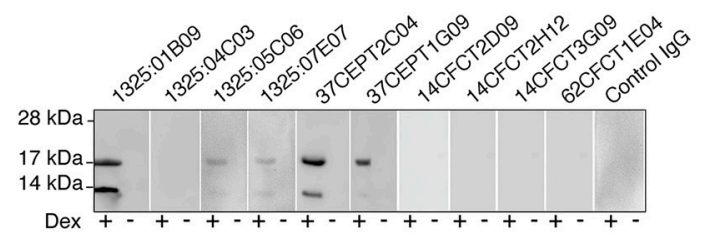

B
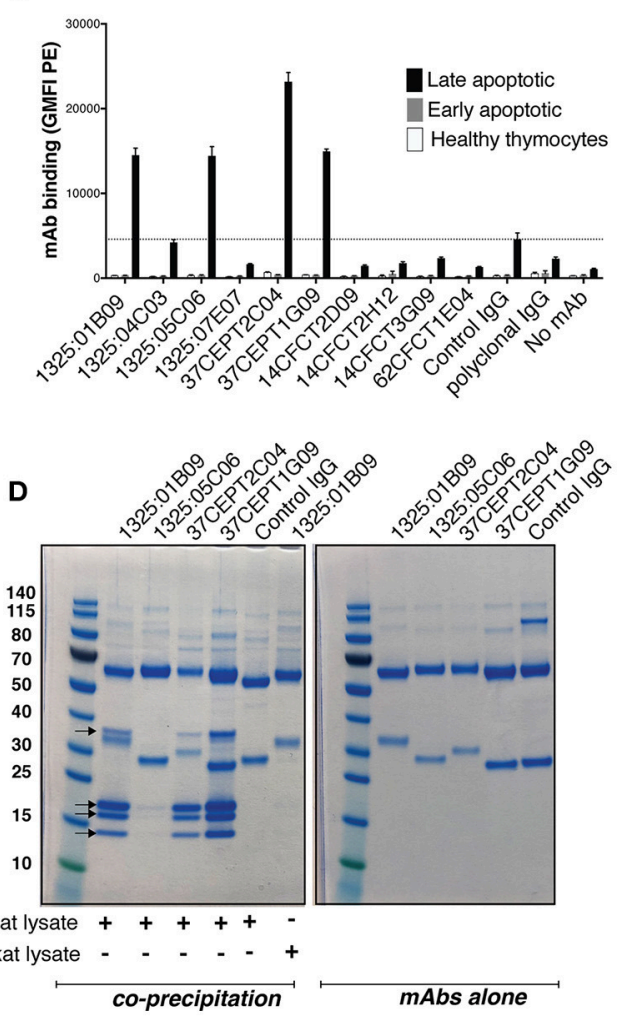

FIGURE 4 | Anti-citrullinated histone ACPA bind apoptotic cells. Flow cytometric analysis revealed that the subset of monoclonal ACPA with citrullinated histone reactivities interacted with apoptotic cells. Binding was assessed by flow cytometry at $10 \mu \mathrm{g} / \mathrm{ml}$ lgG1 using anti-Fas treated human Jurkat T-cells (A) or dexamethasone treated primary murine thymocytes (B) Binding to late apoptotic cells (7AAD positive, Annexin $V$ positive) was compared to early apoptotic cells (7AAD negative, Annexin $\vee$ positive) or healthy cells (7AAD negative, Annexin $\vee$ negative). IgG binding was detected with anti-human IgG PE. A cutoff was set based on the level of binding of the negative control (1362:01E02) to apoptotic cells. (C) Immunoblotting of murine thymocyte lysate revealed that these ACPA bound proteins of $\sim 17 \mathrm{kDa}$ and $14 \mathrm{kDa}$ in apoptotic cells (+ dex), which were not observed in the untreated cells (-dex). (D) Immunoprecipitation of proteins from apoptotic Jurkat cell lysate $\left(400 \mu \mathrm{l}\right.$ from $\left.10^{7} \mathrm{cells} / \mathrm{ml}\right)$ with monoclonal ACPA $(3 \mu \mathrm{g})$ reveal four specific co-precipitated protein bands on SDS-PAGE for 1325:01B09, 37CEPT1G09, 37CEPT2C04, mass spectrometry confirmed that these are different histone proteins. No band was seen for the control non-treated lysates or for a control non-ACPA RA derived mAb (1276:01G09). IgG alone, without cell lysate, are shown in the right panel. Representative figure of three repeat experiments.

reactivity (Supplementary Figure 9). Notably, the samples were screened at 1:40 dilution in concordance with the manufacturer's instructions. In our analysis, this potentially gives some false positivity compared to a more discriminating 1:160 dilution, but avoids that any binding capacity was missed (51).

In order to evaluate ACPA binding in the absence of inflammation, we took advantage of human thymus tissue which feature a dense population of T-cells naturally undergoing apoptosis, and should not express inflammation-related citrullination. Histology staining of fixed and permeabilized human thymus revealed that the tested ANA and apoptotic cell reactive ACPA (1325:01B09 and 37CEPT2C04) also bound intracellular targets (Figure 5B), which co-localized with nuclear staining. The clone 1325:01B09 showed a distinct binding pattern to nuclei with limited overlap with medullary epithelial staining, whereas the clone 37CEPT2C04 exhibited a wider reactivity yet bound only in certain cells within the tissue, which was quantifiable (Figure 5C, Supplementary Figure 10).
Consequently, the ACPA do not bind to nuclei in all cells despite the nuclear reactivity, highlighting the specificity of binding. Flow cytometry confirmed that ACPA bound intracellularly rather than to the surface of human thymocytes (Supplementary Figure 10). Together, the data shows that among the ACPA investigated here a subset can bind to nuclear structures and apoptotic cells, and that the reactivity seems to be primarily directed toward histones.

\section{ACPA mAbs and Apoptotic Cells Increase Citrulline Responses in vivo but the Effect Is Not Dependent on Binding to Nuclear Antigens}

To further query the functional relevance of autoantibody binding to apoptotic cells in vivo, we investigated two monoclonal ACPA, one with anti-nuclear binding (1325:01B09) and one without (1325:04C03), in a murine model of apoptotic 


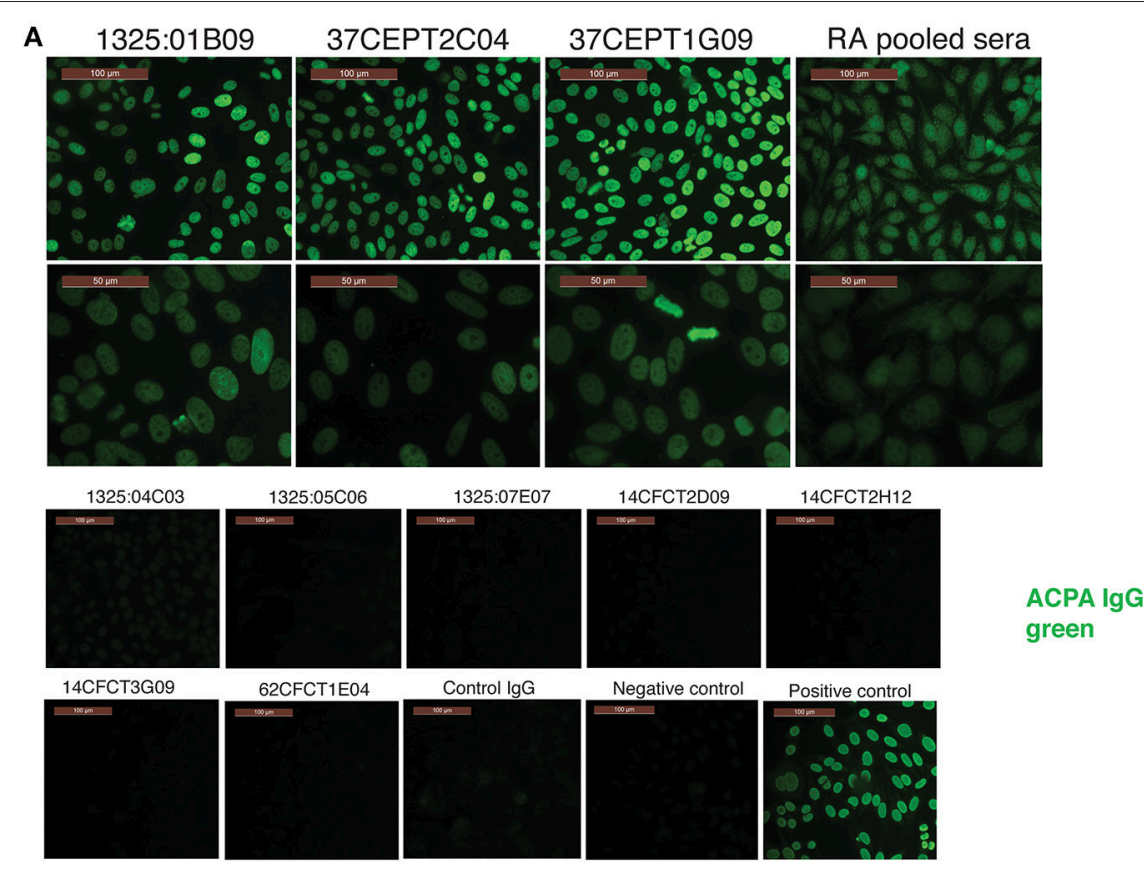

B

1325:01B09

37CEPT2C04

1325:04C03
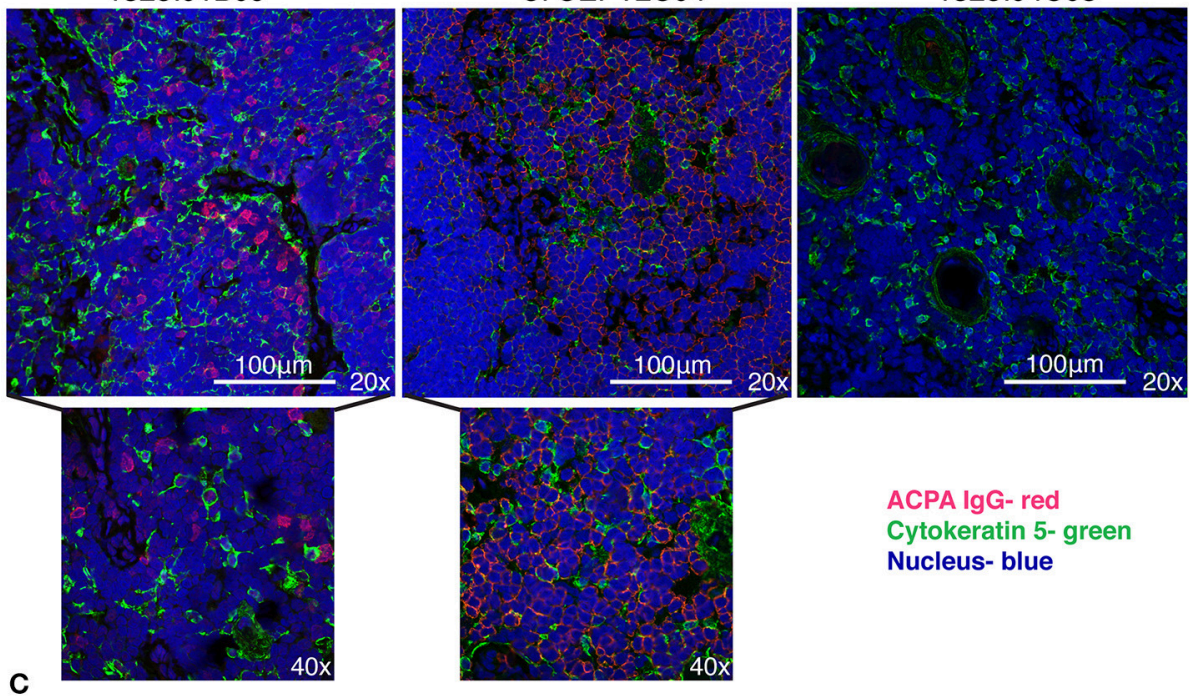

C

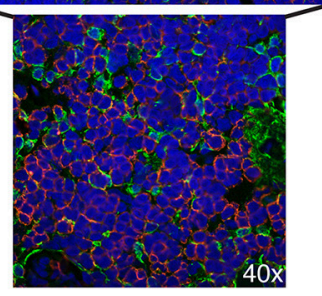

ACPA IgG- red

Cytokeratin 5- green

Nucleus- blue
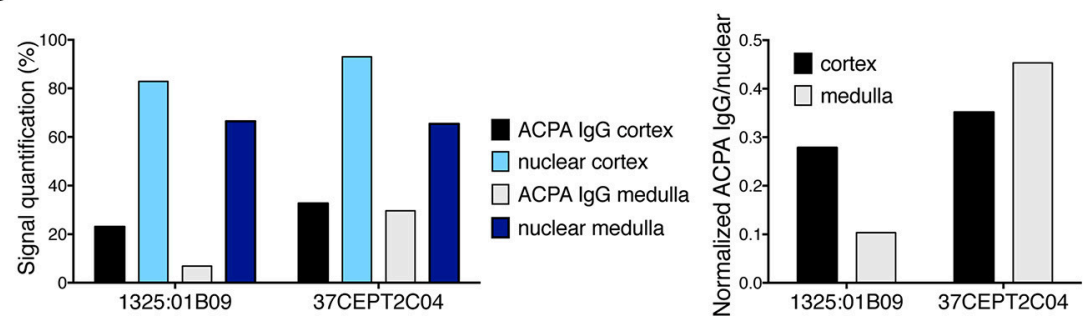

FIGURE 5 | Anti-citrullinated histone ACPA produce nuclear staining pattern. (A) Anti-nuclear autoantibody reactivity (ANA) was determined for ACPA with HEp-2 slides (Inova Diagnostics). Antibody binding is visualized in green. (B) Monoclonal ACPA was evaluated for binding to human thymus tissue from children undergoing cardiac surgery by immunofluorescence staining. IgG binding is visualized in red, nuclei in blue, and medullary epithelial cells by cytokeratin five in green. ACPA hlgG1 mAbs were evaluated at $5 \mu \mathrm{g} / \mathrm{ml}$. The figure shows representative images. (C). Quantification of thymus staining of ACPA mAb IgG (1325:01B09 and 37CEPT2C04) and nuclear staining in medulla compared to cortex areas of the section (\% area covered). Right panel show the cell density normalized quantification (ACPA IgG staining divided by nuclear staining). Details of the quantification can be found in Supplementary Figure 10. 
cell-induced autoreactivity (50, 52, 53). By utilizing validated subclass specific detection reagents (Supplementary Figure 11), injected chimeric murine IgG2a could be separated from endogenous IgG2c and IgG1 responses. Some immunogenicity of the chimeric mIgG2a could be detected at day 35 after injection but did not affect the overall analysis (Supplementary Figure 12). We found that circulating levels of 1325:04C03 were significantly higher than for 1325:01B09 ( $p=0.006$, Figures 6A,B). Intriguingly, trends were observed for an elevated IgG2c immune response to citrullinated fibrinogen (Figure 6) as well as to nuclear proteins (Supplementary Figure 13) in mice treated with 1325:04C03 but not with 1325:01B09, when compared to the injection of ACs alone. No reactivity to citrullinated histone or vimentin could be detected in serum from the mice (Supplementary Figure 14). Notably, the clone 1325:04C03 does not itself react with citrullinated fibrinogen, excluding any risk of the injected $\mathrm{mAb}$ giving false positivity in the ELISA, and the maintained distinct specificities of the two injected mAbs could also be clearly seen when screening cit-vimentin vs. cit-fibrinogen IgG2a in the serum of treated mice (Supplementary Figure 11). Treatment with the clone 1325:01B09 in combination with apoptotic cells instead increase an IgG1 response, although there was a large variation between individual mice. Furthermore, we could observe a significant increase in $\operatorname{IgG} 2 c$ reactivity to citrullinated peptides measured by anti-CCP3 reactivity in the 1325:04C03 injected compared to 1325:01B09 injected mice (Figure 6D), which could not solely be explained by any potential cross-reactivity of the subclass-specific reagent. In 1325:01B09 treated mice, we could also detect increased IgG1 anti-CCP3. While there was a weak correlation between circulating levels of the injected IgG2a and IgG2c anti-CCP3 responses, no such correlation could be seen for IgG1 anti-CCP3 (Supplementary Figure 15). The response was specific since no CCP3 reactivity was seen in mice eliciting other unrelated immune responses such as mice immunized with ovalbumin (Supplementary Figure 16).

In conclusion, free ACPA may increase the immune response to citrullinated antigens but we cannot detect any clear indication of either enhanced or decreased immunological effect by the anti-apoptotic cells reactive ACPA compared to non-reactive ACPA in apoptotic cell injected mice. This may be consistent with the fact that the anti-apoptotic cell ACPA mAbs did not mediate phagocytosis of apoptotic cells in vitro (data not shown). Yet, our data suggest that circulating ACPA in combination with apoptotic cells may mediate induction of autoreactivity to citrullinated epitopes in vivo, while apoptotic cells alone induce ANA and possibly a more polyreactive response to full-length citrullinated protein.

\section{ACPA Monoclonals With Anti-nuclear Reactivity Display PAD-Independent Binding to Neutrophils and NETs}

We next explored how anti-nuclear ACPA reactivities were associated with binding to activated neutrophils and NETs using two different cell systems; primary human neutrophils and a murine neutrophil system based on differentiation of the estrogen-dependent myeloid stem cell line ECoM-G (46). Stimulation with PMA for human cells and ionomycin for murine cells induced in vitro NETosis reactions that could be evaluated by microscopy fluorescent staining of nucleic acid.

The ACPA clones (1325:01B09, 37CEPT1G09, 37CEPT2C04, 1325:05C06) showed strong binding to PMA-stimulated human neutrophils exhibiting NETosis, as well as ionomycin stimulated cells (Figure 7). During NETosis, these ACPA mAbs co-localized with both nuclear targets and NET components. Notably, the clone 1325:05C06, which featured apoptotic cells binding but no HEp-2 ANA reactivity, was positive for NET binding (Figure 7). The 1325:04C03 clone, which lacked nuclear reactivity, instead showed a cytoplasmic binding pattern in activated neutrophils together with a strong NET binding, and did not bind to unstimulated cells. The binding of ACPA mAbs to human neutrophil NETs were confirmed in the ionomycin stimulated ECoM-G murine cells (Figure 7). Opposite to the human system, ionomycin induced higher ACPA binding than PMA stimulation. Importantly, flow cytometry analysis of ACPA binding to murine neutrophils was able to confirm and quantify the different binding reactivities from the human neutrophil study (Figure 8). For example, the clone 1325:04C03 displayed more intracellular than surface binding when comparing protocols with or without permeabilization. Notably, while flow cytometry can to some extent be used for detecting NET-products intracellularly (with permeabilization) as well as exposed on the cell surface (without permeabilization) during activation, it may not detect neutrophils fully in NETosis as these may be too sticky for the analysis. The ACPA clones 1325:01B09, 37CEPT2C04, and 37CEPT1G09 all possessed high intracellular binding consistent with nuclear-binding (Figure 8).

In addition, the ACPA mAbs were evaluated for reactivity to primary murine bone marrow cells (Supplementary Figure 17). Intriguingly, the cytoplasmic neutrophil reactive ACPA clone 1325:04C03 displayed significantly higher binding to differentiated (linage positive) cells while the other clones (1325:01B09, 37CEPT2C04, and 37CEPT1G09) exhibited higher binding to precursor cells (Supplementary Figure 17). In the ECoM-G differentiated neutrophils, we could also distinguish two cell subsets based on Ly6G expression with different ACPA-binding for some mAbs, yet these results may not be easily translated into the situation in primary cells.

As PAD4-mediated citrullination has been reported to be a crucial step in NETosis (16), we questioned whether PAD4 contributed to the observed differences in ACPA mAb binding to activated neutrophils and NETs. Notably, in these experiments we utilized Ca-dependent ionomycin induced NETosis, a protocol that is considered to induce high level of citrullination. As shown in Figure 8A, the addition of a high dose of PAD4 inhibitor (Cl-amidine) during ECoM-G stem cell-to-neutrophil differentiation significantly reduced binding of 1325:04C03 after ionomycin stimulation, whilst binding of the nuclearreactive ACPA were unaffected. To further investigate PAD4dependence, we applied a CRISPR-Cas 9 approach to generate an ECoM-G PAD4 knock-out cell line, whereby the absence 

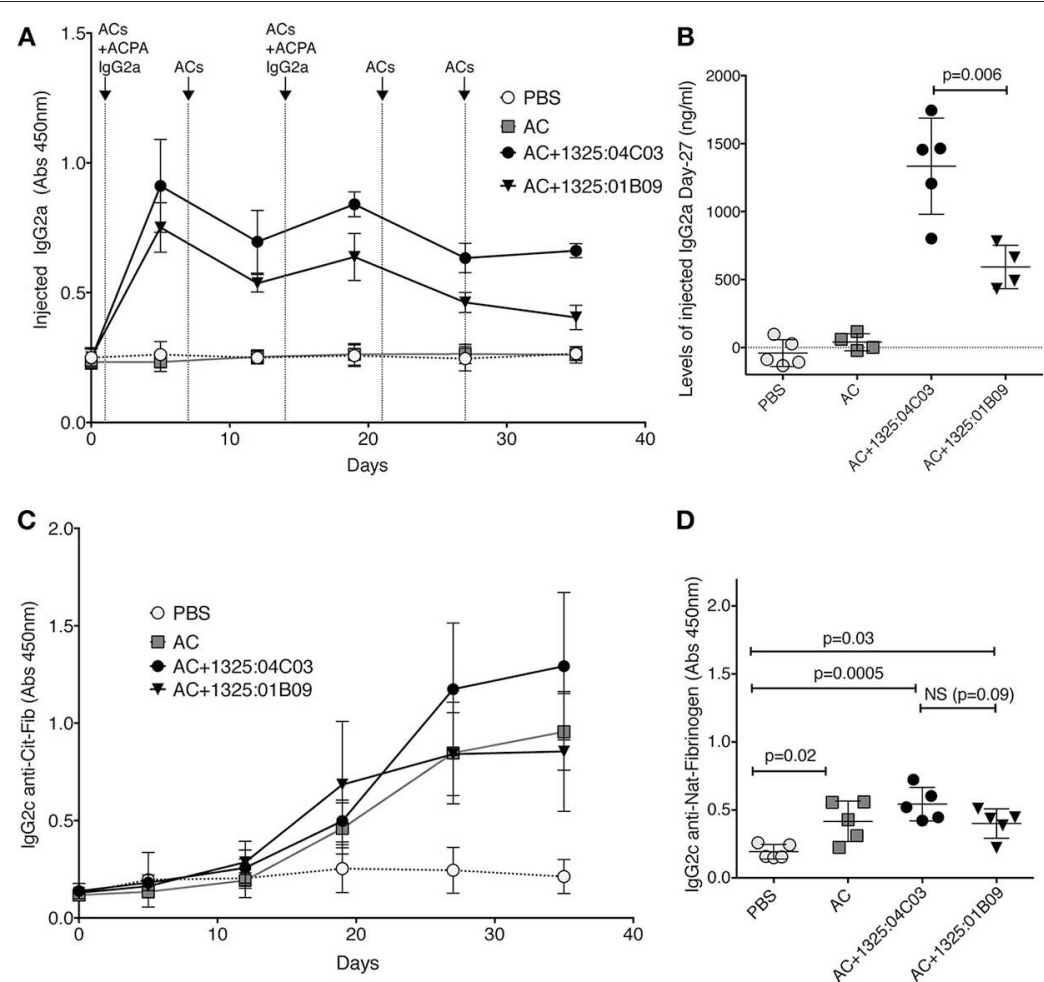

D

E

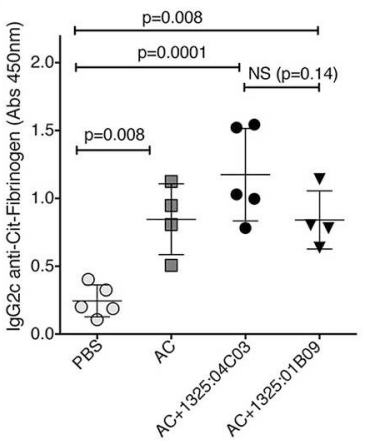

G

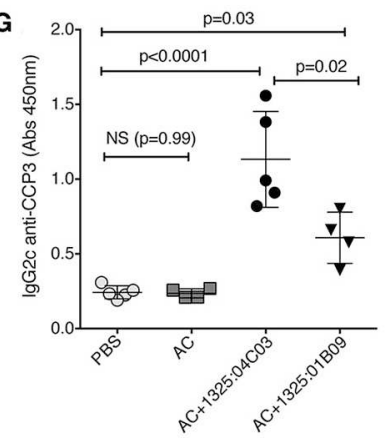

F

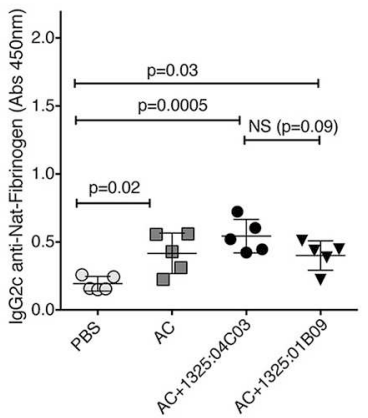

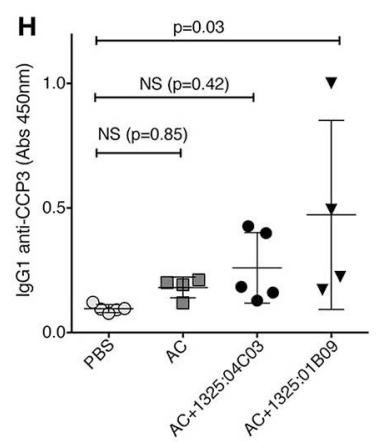

FIGURE 6 | ACPA mAbs in an in vivo model of apoptotic cell induced autoimmunity increase citrulline responses. C57BL/6 mice were injected i.v. with $10^{7}$ apoptotic thymocytes at four occasion, one week apart. One milligrams of murine chimeric IgG2a ACPA mAbs were given in combination with the first and third injection. The figure depicts antibody serum levels determined by sandwich ELISA. Subclass specific detection antibodies (Southern Biotech) were used for separating injected IgG2a from endogenously expressed lgG2C and IgG1. (A) Serum levels of injected ACPA monoclonal mlgG2a antibodies were detected with subclass specific secondary antibody. (B) Serum levels of injected ACPA murine IgG2a on day 27 after the start of the experiment. Unspecific reactivity of the secondary antibody was removed by subtraction of values for pre-injection mice. (C) Induced murine IgG2c to citrullinated human fibrinogen. (D,E) Induced mlgG2c to native and citrullinated fibrinogen at day 27. (F) Induced mlgG1 to citrullinated fibrinogen at day 27. (G,H) Induced serum IgG2c or IgG1 anti-CCP at day 27 detected with a subclass specific detections reagent using the commercial CCP3 coated wells (QUANTA Lite CCP3 IgG, Inova Diagnostics). Groups contained 4-5 mice. P-values are shown from ANOVA analysis with correction for multiple comparisons. 


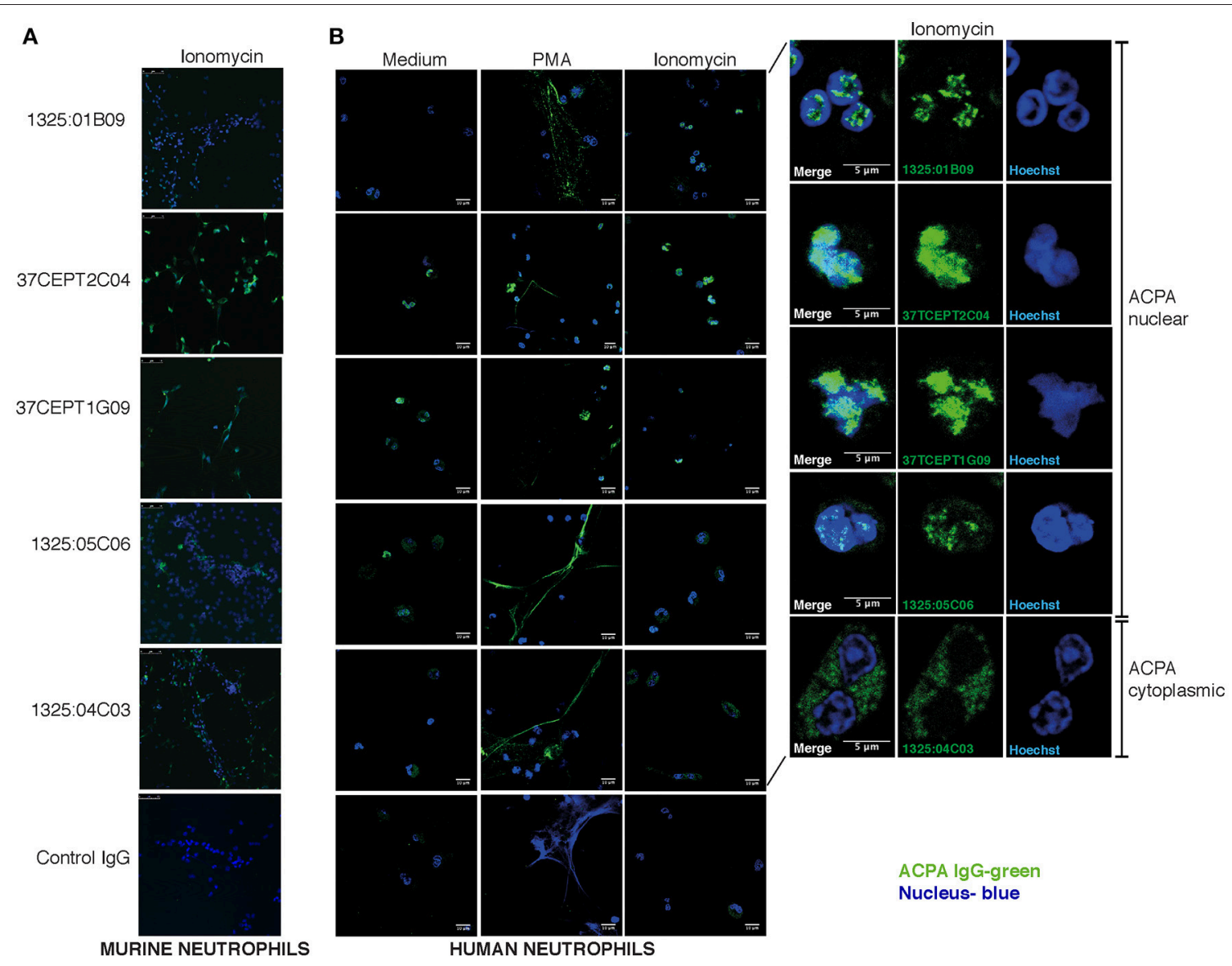

FIGURE 7 | ACPA subgroups can be defined by different binding patterns to neutrophils and NETs. Immunofluorescence staining of ACPA mAb binding to neutrophils and NETs. (A) lonomycin ( $4 \mathrm{~h}, 1 \mu \mathrm{M})$ activated murine ECoM-G differentiated neutrophil cells. (B) Primary human neutrophils that were control stimulated (medium) or stimulated with PMA $(4 \mathrm{~h}, 50 \mathrm{nM})$ or ionomycin $(4 \mathrm{~h}, 1 \mu \mathrm{M})$. ACPA mAb binding to permeabilized and fixed cells was evaluated at $5 \mu \mathrm{g} / \mathrm{ml}$ using hlgG1 versions for murine cell binding and murine chimeric IgG2a mAbs for human cell experiments. ACPA IgG binding is visualized in green and nucleus in blue. The figure shows representative images from three repeated experiments.

of expressed PAD4 protein was confirmed by Western blot (Supplementary Figure 18). Whilst neutrophil differentiation was unaffected in these cells, they displayed reduced ability for NETosis. Despite this, the ANA reactive ACPA mAbs (with a citrullinated histone reactivity profile) maintained comparable reactivity to the PAD4-KO neutrophils (Figure 8A,C,D). The binding of the clone 37CEPT1G09 was reduced, whereas the binding for 1325:01B09 and 37CEPT2C04 mAbs were similar or even increased. However, for the cytoplasmic reactive ACPA 1325:04C03, the binding was significantly lower or absent in the PAD4 KO cells. To further evaluate the independence of PADs and citrullination, we studied binding to ionomycinstimulated bone marrow neutrophils from PAD2 and PAD4 KO mice (54). The nuclear-reactive mAbs showed equally strong binding to the cells from both PAD2 and PAD4 KO mice (Supplementary Figure 19). Yet, we could confirm a reduction in citrullination in both ECoM-G PAD4 CRISPR-KO and cells from the PAD4 KO mouse using a chemical citrulline reactive fluorescent probe, especially in proteins with equivalent in size to histones (Supplementary Figure 20).

\section{The Nuclear Reactive Subset of ACPA Cross-React With Acetylated Epitopes in Histones}

In the light of the PAD-KO experiments, we wondered if the ACPA would cross-react to other PAD-independent post-translational modifications in the nucleus. By using the fluorescent citrulline probe we confirmed that citrullinatedhistones are increased in apoptotic cell lysates and that citrullination can be inhibited by the PAD inhibitor Cl-A (Figure 9). Yet, $\mathrm{Cl}-\mathrm{A}$ did not affect the ACPA-histone binding in Western blot. Moreover, detailed mass spectrometry analysis from immunoprecipitation experiments revealed that antinuclear ACPA captured acetylated histone proteins rather than citrullinated histones, and acetyl-lysine (Ac) peptides from acetylated His2B, His3.1, and His4 were identified (Supplementary Tables 2, 3) whereas no citrullinated peptides were detected. Furthermore, in Western blot of treated Jurkat cells, we detected significantly increased $\mathrm{mAb}$ binding using the broad histone deacetylase (HDAC) inhibitor trichostatin A 
A

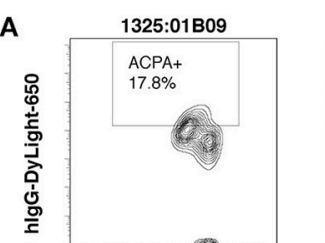

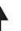
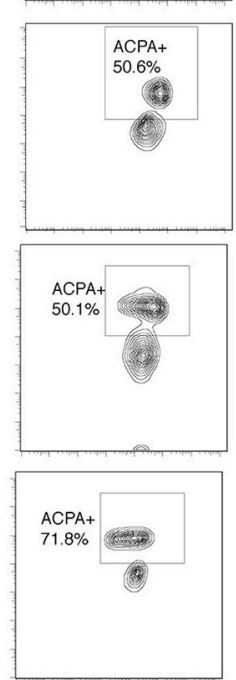
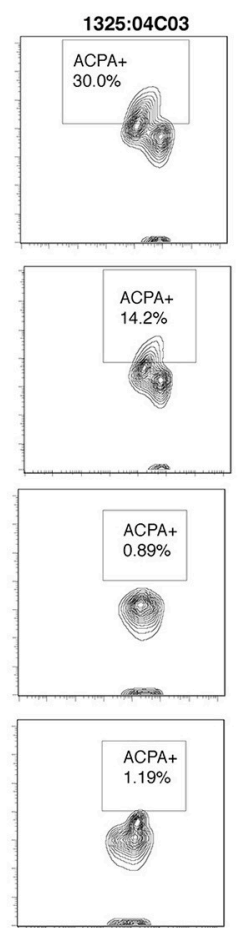

B
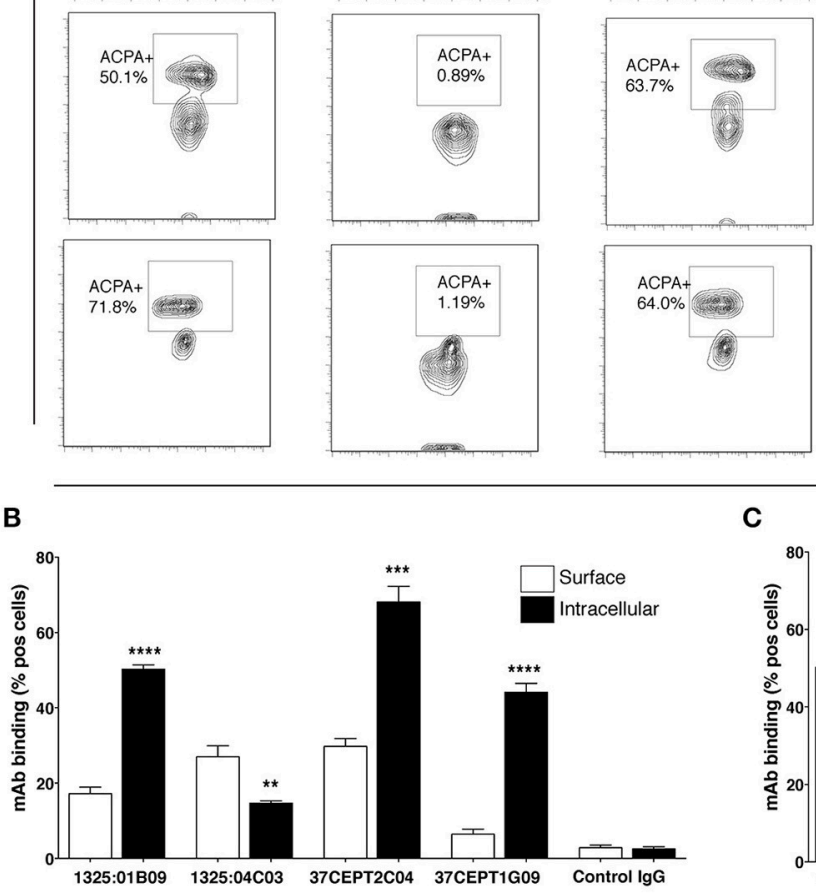

C
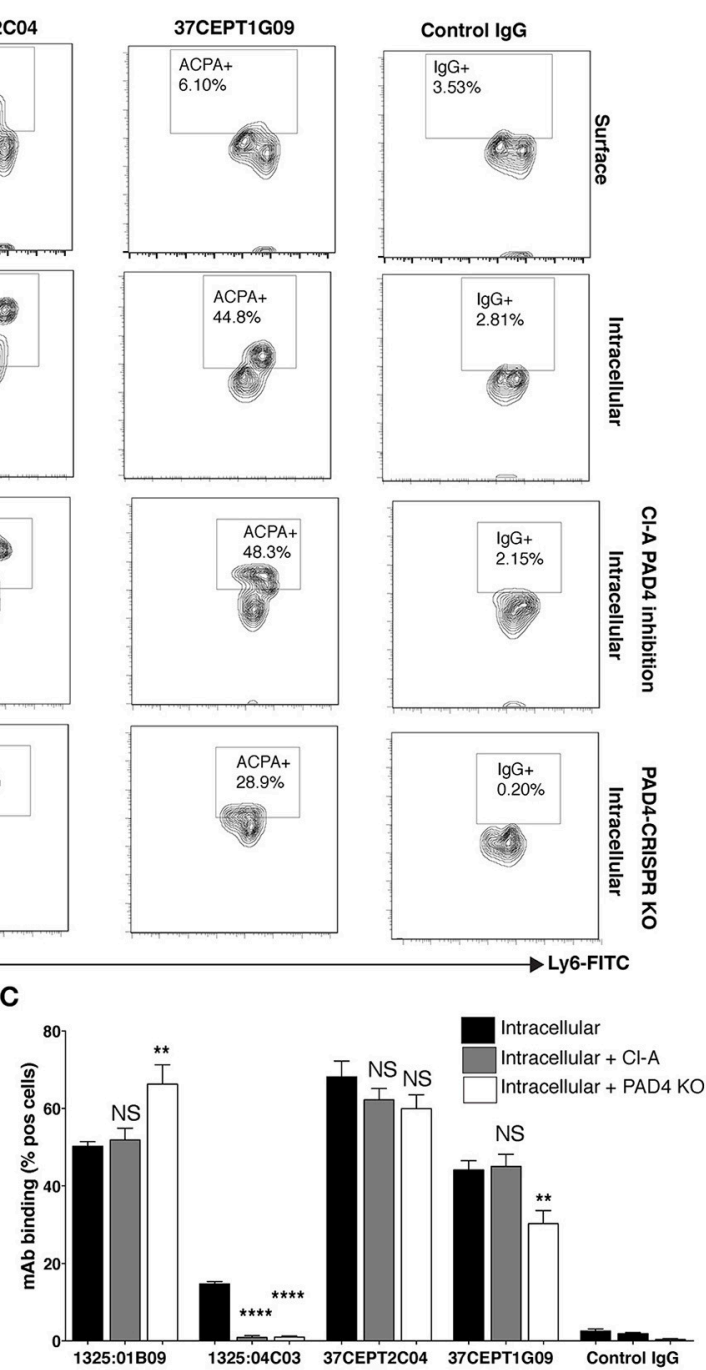

D

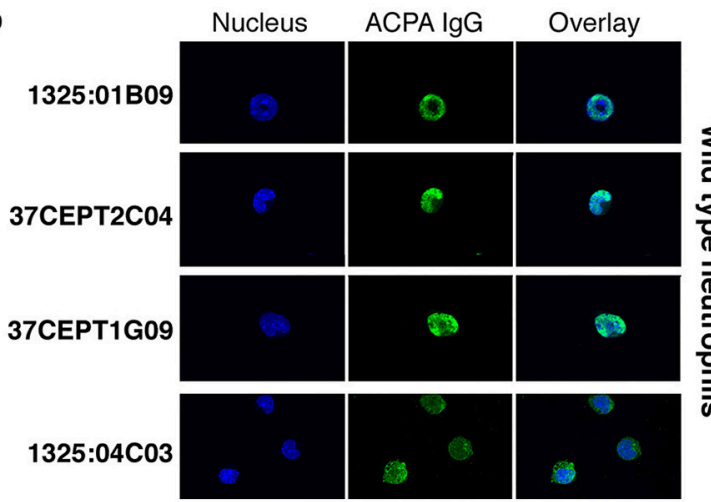

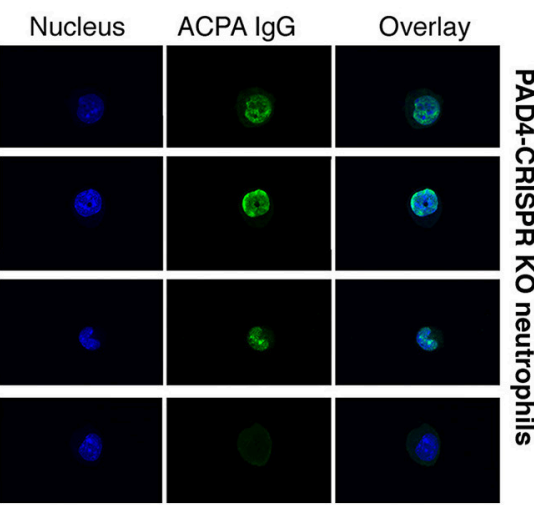

FIGURE 8 | Anti-nuclear ACPA binding to neutrophils is not dependent on PAD4. Flow cytometry binding of human ACPA monoclonal antibodies (10 $\mu \mathrm{g} / \mathrm{ml}$ DyLight-650 hlgG1) to neutrophil differentiated murine ECoM-G cells after ionomycin stimulation ( $4 \mathrm{~h}, 1 \mu \mathrm{M})$. Binding was evaluated with and without permeabilization using the Foxp3 kit (eBioscience) showing surface staining compared to intracellular staining (A,B). ACPA binding was also evaluated in ECoM-G cells with differentiated in the presence of $\mathrm{Cl}$-Amidine $(\mathrm{Cl}-\mathrm{A}, 100 \mu \mathrm{M})$ for 5 days and to CRISPR-Cas9 PAD4 KO cells $\mathbf{( A , C ) . ~ ( A , B ) ~ s u m m a r i z e ~ t h e ~ f l o w ~ c y t o m e t r y ~ \% ~ b i n d i n g ~}$ (Mean and SD) for triplicate conditions in one representative experiment. The figure shows representative images from three repeated experiments. ${ }^{* *} p<0.01-0.001$, ${ }^{* * *} p<0.001-0.0001,{ }^{* * * *} p<0.0001$ derived from student $t$-test comparing intracellular binding to surface binding (A) or binding to cells without treatment (B). (D) Immunofluorescence staining of ACPA mAb binding to ionomycin stimulation of wild type ECoM-G neutrophils compared to CRISPR-Cas9 PAD4 KO cells. The figure shows represented images of stimulated cells in early NETosis. 
(TSA) that gives elevated acetylation (Figure 9). The citrulline probe confirmed that citrullination was not significantly affected by HDAC inhibition and anti-Ac-His $2 \mathrm{~B}$ detection showed acetylation of histone 2B (Figure 9). The ACPA mAbs demonstrated consistent binding to two acetylated bands after HDAC inhibition with MW consistent with different histone isoforms (e.g., His $2 \mathrm{~B} / 3$ and His4). We next used ELISA to determine binding to synthetic acetylated peptides covering know histone acetylation residues (Ac-His2B K12; Ac-His4 K5, K8, K12, K16), and we could confirm that only the ACPA with ANA, apoptotic cell, and neutrophil nuclear patterns, bound to acetylated histone peptides (Figure 9). The ELISA reactivity to acetylated peptides were similar in strength compared to the cit-peptides Cit-Vim60-75 and Cit-Fib $\alpha 563-583$ that represent well-characterized ACPA cittargets (Figure 9, Supplementary Figure 21). While the $\mathrm{mAb}$ 1325:01B09 displayed no detectable binding to any native peptides, 37CEPT1G09 and 37CEPT2C04, and to minor extent 1325:05C06 showed some reactivity also to native lysinecontaining His-peptides at high IgG concentration, however this was to large extent diminished when titrating to lower concentrations. The acetylation-reactivity was also present in polyclonal anti-CCP2 purified ACPA pools from RA patients (Supplementary Figure 22). Furthermore, germline converted versions of the clones 1325:05C06 and 1325:01B09 (10) did not bind acetylated peptides (Supplementary Figure 21). Hence, this reactivity, similar to what has been seen previously for citrullinated peptides (10), are generated by considerable degree of somatic hypermutation and affinity maturation of $\mathrm{B}$ cells in the germinal center. In summary, our results reveal a distinct ACPA subset based on monoclonal antibody reactivity patterns to activated neutrophils and NETs, and highlight a surprising difference in dependence for PAD2/4-citrullination and reactivity to acetylated histones (summarized in Figure 10).

\section{DISCUSSION}

Important new findings presented in this study include the following observations: There is a major heterogeneity among monoclonal ACPA generated from B cells from RA patients; We find that some, but not all, of these monoclonal ACPA show strong anti-nuclear binding patterns including binding to apoptotic cells; These anti-nuclear ACPA also react with activated neutrophils and NETs and the binding of these antibodies is largely independent on PAD-expression and is mediated by acetylation. This is not the case for another ACPA subset that display a citrulline-dependent NET and neutrophil cytoplasmic binding. Taken together, our studies demonstrate how detailed investigation of ACPA reactivity using patientderived monoclonal antibodies, rather than serum polyclonal antibodies, can reveal functional differences of potential pathogenic significance between ACPA subsets. Mechanistically, this may also suggest potential differences in the origin of these subsets, including the $\mathrm{B}$ cell population recruited and the nature of the antigen.
Despite the emerging data on a pathogenic role of ACPA in RA $(2-11,55,56)$, there is still limited knowledge concerning how the detailed specificities of different ACPA relate to functionality or to targeting of different effector cells. Protein-modification can occur in many different situations, and we don't fully understand which processes may initiate break of tolerance and drive the continuous anti-citrulline response in RA. Synovial hypercitrullination has been postulated to be unique for RA pathogenesis (57). Yet, this process is likely more associated with chronic disease than physiological conditions or pre-disease autoimmunity. However, modified antigens generated by cell death and NETosis could instead be hypothesized to play a role in initiating or amplifying autoreactivity. While ACPANET interactions have previously been reported (22), there has been little focus on apoptosis in the context of RA to date. Autoreactivity to components of dead cells and nuclear antigens may reflect a general lack-of-tolerance toward modified molecules generated during apoptosis and such binding has previously been described for the healthy immune system with polyreactive antibodies (58) and natural IgM (59).

We identified histones as a target for ACPA in apoptotic cells and initially focused on citrullinated histone $2 \mathrm{~B}$. Citrullinated histones have previously been shown to be immunostimulatory by themselves, and in vitro formed citrullinated histone-IgG immune complexes stimulated macrophages in a mechanism proposed to occur via TLR-Fc $\gamma$ receptor cross-talk $(8,11)$. However, in our assay, the effect was solely dependent on antigenbinding and $\mathrm{F} c \gamma \mathrm{R}$ activation. Importantly, we demonstrate a significant heterogeneity between different monoclonal ACPA with respect to this type of immunostimulation, as we find that one ACPA clone (1325:01B09) specifically induced proinflammatory cytokine production. Importantly, the finding that ACPA-citrullinated histone immune complexes drive IL-8 production connects these antibodies to this chemokine in early phases of RA. Mechanistically, IL-8 has been shown to be central to causing bone loss and pain behavior in models of early RA $(4,6)$. The degree of ACPA citrullinated peptide cross-reactivity in immune complexes obtained in vivo from RA synovial fluid was recently shown to be associated with the extent of joint destruction and measures of inflammation (56).

An interesting finding highlighted here was that some monoclonal ACPA displayed ANA reactivity. Although 20\% of RA patients have been reported to have serum ANA reactivity, this has not been associated with ACPA status (60). Patient-derived monoclonal ACPA with citrullinated histone and apoptotic cell reactivity were here shown to display ANA HEp-2-staining consistent with chromatin-related patterns. This binding had more similarity to the dense fine speckled or AC-2 pattern according to the ICAP nomenclature than to the regular anti-native histone pattern (44). Additionally, the ANA-positive ACPA subset exhibited strong binding to nuclear structures in human thymus. The differential binding to the nuclei of distinct cells, particularly with the clone 1325:01B09, may suggest diversity in nuclear protein modification, potentially in association with differentiation or proliferation. Importantly, the ACPA mAbs did not display any significant binding to purified native histones, nucleosomes or dsDNA complexes in 


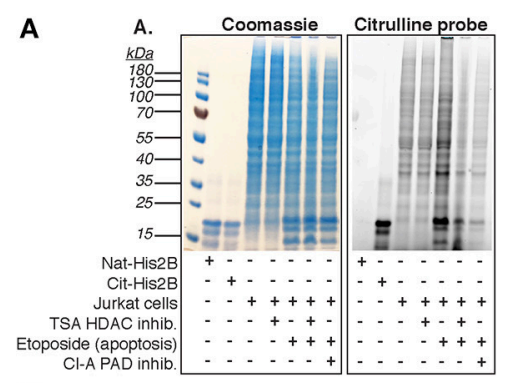

C

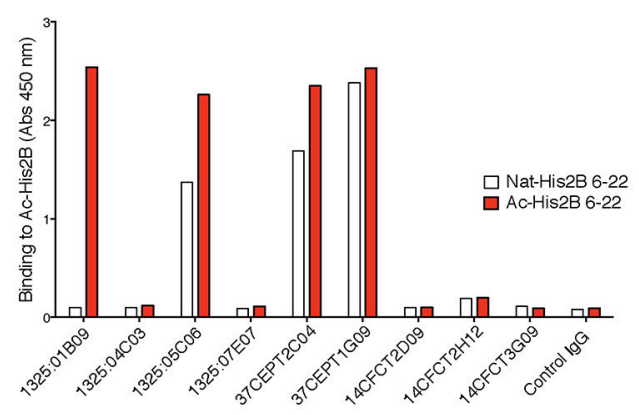

B

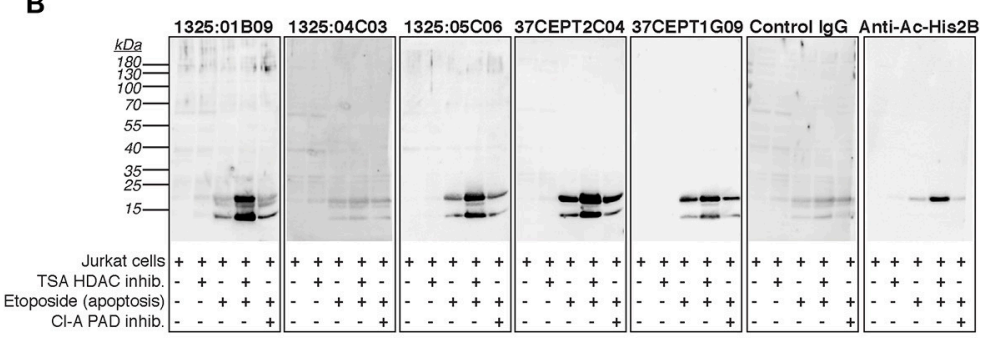

D

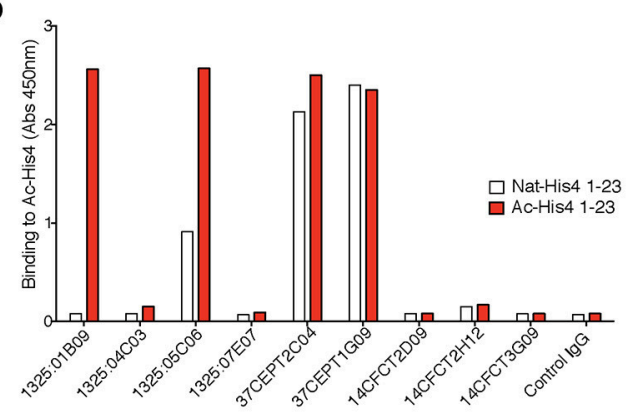

E

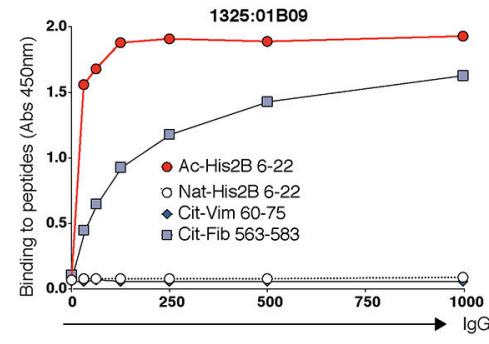

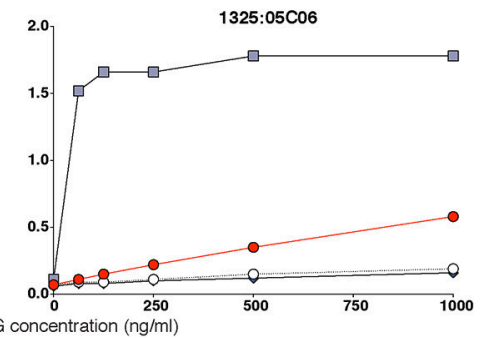

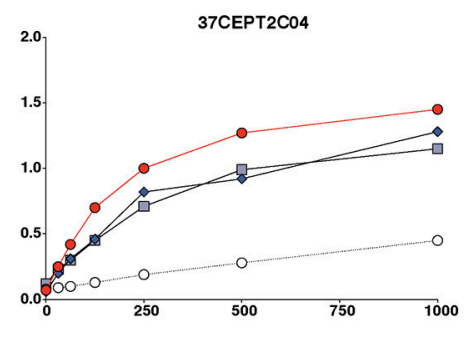

FIGURE 9 | Citrulline-independent ACPA mAb binding to histones in NETs and nuclei can be explained by binding to acetylated histone epitopes. (A) Citrullination was evaluated using a rhodamine-based chemical probe in Jurkat cells treated with the $100 \mathrm{ng} / \mathrm{ml}$ histone deacetylase (HDAC) inhibitor trichostatin A (TSA) or $20 \mu \mathrm{M}$ of the PAD inhibitor $\mathrm{Cl}$-amidine (Cl-A) $3 \mathrm{~h}$ before induction of apoptosis with $25 \mu \mathrm{M}$ etoposide overnight. HDAC inhibition leads to increased acetylation but no significant change in citrullination. The right panel shows the cell lysates separated by SDS-PAGE and stained with the citrullination probe and the left panel shows the same gel stained with Coomassie. (B) Western blot binding of ACPA hlgG1 monoclonal antibodies (5 $\mu \mathrm{g} / \mathrm{ml})$ to acetylated histones in treated Jurkat cell lysates detected with rabbit anti-human IgG HRP. Acetylated histone 2B was detected as a control using a specific antibody (Cell Signaling). Reactivities of the ACPA IgG mAbs $(5 \mu \mathrm{g} / \mathrm{ml})$ to biotinylated acetylated peptides from histone 2B (Ac-His2B 6-22) (C) and histone 4 (Ac-His4 1-23) (D) were confirmed with ELISA. (E) ELISA titration of three acetylated-histone positive ACPA mAbs to acetylated histone 2B peptide (Ac-His2B 6-22), compared to the native lysine peptide and two citrullinated peptides from vimentin (cit-Vim 60-75) and fibrinogen alpha chain (cit-Fib 563-583), at the indicated IgG concentrations. The figure shows representative data from three repeated experiments.

control ANA-antigen assays, and did not display any similarities with reported lupus-associated or murine anti-histone or antiDNA reactivities $(61,62)$.

Increased intracellular calcium levels during apoptosis may induce increased PAD enzyme activity (63) and if citrullination of histones occurs it could potentially contribute to histone remodeling. Although histone citrullination has been hypothesized to be a prominent feature during apoptosis and autophagy, it had not been investigated previously in this context. Citrullination in neutrophils has been reported to not be increased during apoptosis (64), yet, our studies using the chemical rhodamine citrulline-probe clearly indicate an increase of citrullinated histone protein during apoptosis in Jurkat cells.

Increased amounts of histone proteins within the soluble phase of cell lysates were also detected, consistent with a previous finding that histones are released from nucleosome complexes during apoptosis (65) and are more accessible for captured by anti-histone antibodies (66). Besides increased PAD activity, apoptosis may also lead to increased translocation and exposure of modified antigens on the cell surface, or breakdown of membrane structures leading to higher accessibility to intracellular materials for antibody binding. Therefore, it can be hard to discriminate between increased accessibility or increased expression in apoptotic cell assays. Yet, our mAb-binding results were consistent between flow cytometry and western blot analysis of whole cell lysate, supporting that the antigen level is indeed elevated during apoptosis. Citrullination of vimentin has been suggested to be important during apoptosis, contributing to morphological changes (67). However, no binding to apoptotic cells was seen for the investigated ACPA clones with documented high binding to citrullinated vimentin (e.g., 1325:04C03). Hence, 


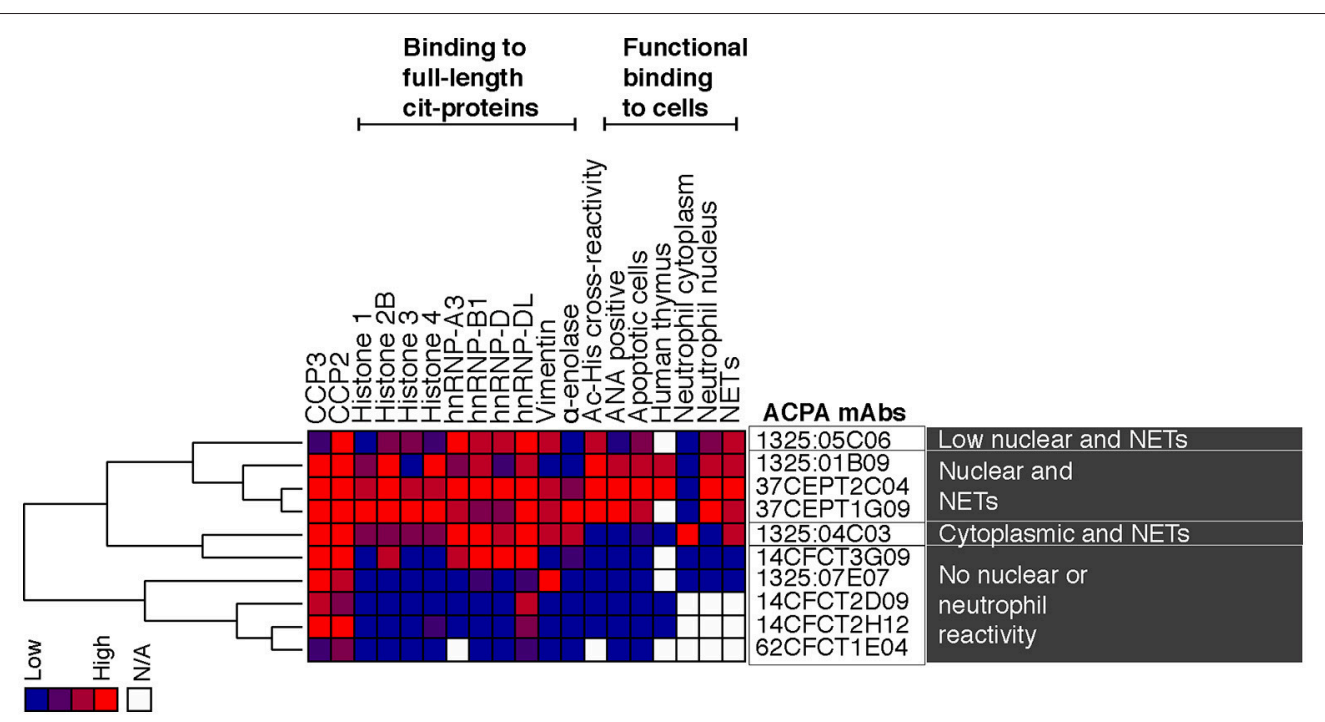

FIGURE 10 | Summary of reactivity patterns for evaluated monoclonal ACPA. The figure summarizes ELISA binding reactivities for the investigated RA-derived human ACPA monoclonal antibodies together with results from cell interaction studies. The investigated single cell isolated ACPA monoclonal antibodies were derived from synovial plasma cells (1325:01B09, 1325:04C03, 1325:05C06, 1326:07E07) or antigen-tetramer captured circulating memory B cells (37CEPT1G09, 37CEPT2C04, 14CFCT2D09, 14CFCT2H12, 14CFCT3G09, 62CFCT1E04) from four different CCP-positive RA patients (RA1325, RA37, RA14, and RA62) (5, 10). The antibody binding was normalized $0-4$ and the monoclonal clones were analyzed by hierarchical clustering with complete linkage using Cluster 3.0 and visualized by Java Treeview. The heat-map shows high reactivity in red, intermediate in purple and negative results in blue.

our results demonstrate that citrullination of vimentin is limited during the different apoptosis pathways included in our investigation or is not accessible for detection (i.e., anti-Fas, etoposide, or dexamethasone, in T-cells).

Importantly, nuclear ACPA mAb binding to apoptotic cells could only partly be explained by reactivity to elevated cit-histones. We therefore concluded that the ACPA may instead bind to another apoptosis-associated histone posttranslational modification with similar chemical properties. Histone acetylation is a neutrally charged lysine modification that is associated with chromatin relaxation and gene activation, but is also increased in apoptosis (68). Indeed, the ACPA subset with anti-apoptotic cell reactivity was found to have strong binding to acetylated histones within lysates of stimulated cells and direct reactivity to acetylated histone $2 \mathrm{~B}$ and 4 peptides. This Ac-histone reactivity fully explained the PADand citrulline-independent binding of certain ACPA to nuclear structures.

Cross-reactivity of ACPA mAbs to acetylated histones peptides has not been previously reported. Polyclonal RA antibodies have been shown to contain reactivity to acetylated residues using a synthetic, not naturally occurring, construct based on a vimentin peptide whereby the arginine/citrulline residue was exchanged for acetyl-lysine $(69,70)$. Our ELISA results with ACPA mAbs show that only the antibodies recognizing a modified consensus motif present in the vimentin peptide have the potential to bind these carb- and acetylsynthetic vimentin peptides (10).

In the current study, the acetyl-histone peptides are containing glycine in the -1 position and therefore cross-reactive
mAbs are only found among the mAbs binding to a CitGly dominating consensus motif. The clone 1325:01B09 has previously been determined to also cross-react to carbamylated (homocitrullinated, carb) peptides displaying the Carb-Gly consensus motif (10). Identified carb-peptides among 49,211 peptides (Roche NimbleGen microarray) included peptides from histone $2 \mathrm{~B}$ and histone 4 covering the known lysine acetylation sites that we included in the Ac-peptides in the present study (His2B K12; His4 K6, K8, K12). Thus, some overlap in recognition of carbamylating and acetylation may be expected. In conclusion, cross-reactivity of ACPA to acetylated histones represents a new autoreactivity in RA which is observed in a subset of ACPA autoantibodies. The acetylation reactivity was equal or stronger than citrulline reactivity and potentially representing a more dominant binding for these clones in vivo. Owing to the extensive modified protein cross-reactivities, perhaps these and other ACPA should rather be considered as AMPA.

In a previous report, proteomic analysis of activated neutrophils identified citrullinated Histone $2 \mathrm{~B}$ as a target of anti-modified citrulline antibodies, which possessed the capacity to induce macrophage cytokine production and propagated neutrophil activation (8). PAD4-dependent NETosis has previously been shown to occur under certain forms of stimulation $(16,71,72)$, and we confirm a reduction in Ca-dependent NETosis in the CRISPR-PAD4 KO cells. NET citrullinated histone 4 has additionally been to shown to be a significant target of serum antibodies and ACPA reactivity to cit-His4 peptides is commonly detected in RA patients, which correlates with anti-CCP2 levels (73). Furthermore, monoclonal 
ACPA binding capacity to NETs has been reported previously (22). Yet, here we demonstrate the nuclear-reactive ACPA subset interact strongly with activated neutrophils and NETs in a PAD-independent manner. The anti-nuclear ACPA maintained strong binding to the PAD4 KO cells as well as cells from PAD2 KO mice whilst binding was completely lost for the anti-cytoplasmic ACPA (1325:04C03) that displayed PAD4dependent binding. Hence, we conclude that the anti-nuclear subset of ACPA bind strongly to NETs through mechanism that are likely involving acetylated histones, similarly to what was seen in the apoptotic cells. Acetylation of histones has been demonstrated in NETosis and have been reported to be immunostimulatory as well as a suggested autoantibody target in SLE (74-76), but has not yet been discussed in the context of RA. The difference in the studied ACPA mAb binding patterns further emphasizes the appearance of distinct ACPA subsets with potentially different functionality. It is important to state that the murine in vitro cell system utilized Ca-dependent NETosis, which may not fully mimic NETosis in vivo or NETosis induced by microbial stimuli, and gives a higher level of citrullination, although not to the same extent as leukotoxicinduced hypercitrullination (77). However, our starting point was the investigation of $\mathrm{mAb}$-binding and interestingly we observed differences in stimulation of human blood neutrophils compared to murine bone marrow neutrophils. In the human system, we had equal binding of the different subtypes of ACPA to PMA compared to ionomycin stimulated cells while for murine cells we observed higher binding in ionomycin stimulated cells. Most importantly for the current study, the nuclear and cytoplasmic binding patterns of the different ACPA clones, driven either by acetylation or citrullination, respectively, remained consistent between neutrophil origin.

The fact that monoclonal ACPA clones with different finespecificity patterns may mediate different functionality related to different symptoms of RA, is to some extent supported by our previous studies. For example, the 1325:04C03 clone has been demonstrated to have pathogenic properties by enhancing osteoclastogenesis and mediate osteoclast-driven IL8 production, whereas the investigated monoclonal antibodies from the nuclear reactive subset did not possess such effects (10). We have also observed that certain monoclonal ACPA from the nuclear reactive subset enhance endotoxin-induced arthritis in vivo (5).

In conclusion, we demonstrate that certain ACPA specifically bind to nuclear and NETosis associated antigens. One type of ACPA reactivity to nuclear antigens in neutrophils and NETs is PAD-independent and driven by acetylation, whilst another subset of ACPA reactivity, with a cytoplasmic and peri-nuclear pattern, is dependent on PAD4 expression and citrullination. The studied monoclonal antibodies are bona fide highly mutated anticitrulline antibodies without any unspecific polyreactivity and possess identical or similar properties to monoclonal antibodies published by other research groups $(11,78)$. They display substantial modified protein cross-reactivity due to the fact that they recognize distinct consensus peptide motifs, present in numerous full-length proteins, and our data now reveals that this motif can include different neutrally charged posttranslational modifications including citrulline, homo-citrulline, and acetylation. This substantially expands our understanding of AMPA and emphasizes the considerable overlap between different reactivities to post-translational modifications. It also evokes important questions about which protein modifications primarily drive the initiation of autoimmunity, as well as the continuation of pathogenic responses in RA. Importantly, the current study emphasizes that ACPA can, and probably should, be divided into different subsets based on their cell-reactivity and modification cross-reactivity patterns. We propose that this subdivision of ACPA, now made possible with the availability of an increasing number of well-characterized monoclonal ACPA from RA patients, will lead to a better understanding of the pathogenic roles of different ACPA in relation to mechanisms and symptoms in RA, thereby enabling better interventions in this disease.

\section{AUTHOR CONTRIBUTIONS}

All authors were involved in drafting the article or revising it critically for important intellectual content, and all authors approved the final version to be published. KL, GW, CG, $\mathrm{VM}, \mathrm{FW}$, and LK designed the studies and interpreted the data. JS, PT, DM, and VM designed and performed single cells isolation of monoclonal ACPA and initial characterization of the antibodies. KL, GW, KC, DZ, CG, and PS performed ACPA binding experiments and analyzed data. BM, PS, and KS worked on expression and validation of recombinant autoantigen. RS produced and validated monoclonal antibodies. DZ performed PMBC assays, serological patient screenings, and analyzed clinical data. MJK provided materials and input on PAD KO cell experiments and interpretation of data. JR provided interpretation of ANA reactivity patterns and input on immune complex methodology. EO performed mass spectrometry experiments and analysis. MG and MCIK designed and performed in vivo murine studies. CL and OE worked on studies of ACPA binding to human thymus. KL and CG wrote the first manuscript draft. All authors participated in discussions and the finalizing of the manuscript.

\section{FUNDING}

This work was supported by the Swedish Research Council, the Swedish Rheumatism Association, King Gustaf V's 80year Foundation, the Region Västra Götaland (ALFGBG718021), IngaBritt, and Arne Lundbergs Research Foundation, NIH/NIGMS (MSTP T32 GM008244, PT), Rheumatology Research Foundation (Disease Targeted Innovative Research Grant, Within our Reach Award, DM), and the EU/EFPIA Innovative Medicines Initiative (IMI) 2 Joint Undertaking projects BTCure 115142 and RTCure 777357. Funded in part by NIAMS (ZIAAR041199).

\section{ACKNOWLEDGMENTS}

We thank UCB Pharma for support with technology and antibody production as well as financial support for $\mathrm{KL}$ postdoctoral training within the IMI BTCure project, and 
Stephen Rapecki (UCB Pharma) for scientific discussions. We would also like to thank Lena Israelsson and Dr. Monika Hansson (Karolinska Institutet) for support in antibody validation and characterization. In addition, we thank Lena Israelsson, Eva Jemseby, and Julia Boström for managing the cohorts biobanking and handling of blood samples. We thank Johanna Källström (Uppsala University Hospital) for help with ANA-line blot analysis and Dr. Radha Thyagarajan (Karolinska Institutet) for phagocytosis experiments. We thank Drs. Heidi Wähämaa, Anca Catrina, and Karin Lundberg

\section{REFERENCES}

1. Malmström V, Catrina AI, Klareskog L. The immunopathogenesis of seropositive rheumatoid arthritis: from triggering to targeting. Nat Rev Immunol. (2017) 17:60-75. doi: 10.1038/nri.2016.124

2. Engdahl C, Bang H, Dietel K, Lang SC, Harre U, Schett G. Periarticular bone loss in arthritis is induced by autoantibodies against citrullinated vimentin. $J$ Bone Miner Res. (2017) 32:1681-91. doi: 10.1002/jbmr.3158

3. Harre U, Georgess D, Bang H, Bozec A, Axmann R, Ossipova E, et al. Induction of osteoclastogenesis and bone loss by human autoantibodies against citrullinated vimentin. J Clin Invest. (2012) 122:1791-802. doi: 10.1172/JCI60975

4. Krishnamurthy A, Joshua V, Haj Hensvold A, Jin T, Sun M, Vivar N, et al. Identification of a novel chemokine-dependent molecular mechanism underlying rheumatoid arthritis-associated autoantibody-mediated bone loss. Ann Rheum Dis. (2016) 75:721-9. doi: 10.1136/annrheumdis-2015-208093

5. Titcombe PJ, Wigerblade G, Sippl N, Zhang N, Shmagel AK, Sahlstrom P, et al. Pathogenic citrulline-multispecific B cell receptor clades in rheumatoid arthritis. Arthritis Rheum. (2018) 70:1933-45. doi: 10.1002/art.40590

6. Wigerblad G, Bas DB, Fernades-Cerqueira C, Krishnamurthy A, Nandakumar KS, Rogoz K, et al. Autoantibodies to citrullinated proteins induce joint pain independent of inflammation via a chemokine-dependent mechanism. Ann Rheum Dis. (2016) 75:730-8. doi: 10.1136/annrheumdis-2015-208094

7. Khandpur R, Carmona-Rivera C, Vivekanandan-Giri A, Gizinski A, Yalavarthi S, Knight JS, et al. NETs are a source of citrullinated autoantigens and stimulate inflammatory responses in rheumatoid arthritis. Sci Transl Med. (2013) 5:178ra40. doi: 10.1126/scitranslmed.3005580

8. Sohn DH, Rhodes C, Onuma K, Zhao X, Sharpe O, Gazitt T, et al. Local joint inflammation and histone citrullination in a murine model of the transition from preclinical autoimmunity to inflammatory arthritis. Arthritis Rheum. (2015) 67:2877-87. doi: 10.1002/art.39283

9. Sokolove J, Zhao X, Chandra PE, Robinson WH. Immune complexes containing citrullinated fibrinogen costimulate macrophages via toll-like receptor 4 and fcgamma receptor. Arthritis Rheum. (2011) 63:53-62. doi: 10.1002/art.30081

10. Steen J, Forsström B, Sahlström P, Odowd V, Israelsson L, Krishnamurthy A, et al. Human plasma cell derived monoclonal antibodies to posttranslationally modified proteins recognize amino acid motifs rather than specific proteins. Arthritis Rheum. (2018). doi: 10.1002/art.40699. [Epub ahead of print].

11. Elliott SE, Kongpachith S, Lingampalli N, Adamska JZ, Cannon BJ, Mao R, et al. Affinity maturation drives epitope spreading and generation of proinflammatory anti-citrullinated protein antibodies in rheumatoid arthritis. Arthritis Rheum. (2018) 70:1946-58. doi: 10.1002/art.40587

12. Witalison EE, Thompson PR, Hofseth LJ. Protein arginine deiminases and associated citrullination: physiological functions and diseases associated with dysregulation. Curr Drug Targets (2015) 16:700-10. doi: 10.2174/1389450116666150202160954

13. Makrygiannakis D, Revu S, Engstrom M, af Klint E, Nicholas AP, Pruijn GJ, et al. Local administration of glucocorticoids decreases synovial citrullination in rheumatoid arthritis. Arthritis Res Ther. (2012) 14:R20. doi: 10.1186/ar3702

14. Foulquier C, Sebbag M, Clavel C, Chapuy-Regaud S, Al Badine R, Mechin MC, et al. Peptidyl arginine deiminase type 2 (PAD-2) and PAD-4 but not PAD-1, PAD-3, and PAD- 6 are expressed in rheumatoid arthritis synovium in close
(Karolinska Institutet) for the CCP2-purified polyclonal ACPA pool. We are grateful to Dr. Scott Coonrod (Cornell University) for generating and generously sharing the PAD KO mice.

\section{SUPPLEMENTARY MATERIAL}

The Supplementary Material for this article can be found online at: https://www.frontiersin.org/articles/10.3389/fimmu. 2018.03033/full\#supplementary-material

association with tissue inflammation. Arthritis Rheum. (2007) 56:3541-53. doi: 10.1002/art.22983

15. Knight JS, Subramanian V, O’Dell AA, Yalavarthi S, Zhao W, Smith CK, et al. Peptidylarginine deiminase inhibition disrupts NET formation and protects against kidney, skin and vascular disease in lupus-prone MRL/lpr mice. Ann Rheum Dis. (2015) 74:2199-206. doi: 10.1136/annrheumdis-2014-205365

16. Li P, Li M, Lindberg MR, Kennett MJ, Xiong N, Wang Y. PAD4 is essential for antibacterial innate immunity mediated by neutrophil extracellular traps. J Exp Med. (2010) 207:1853-62. doi: 10.1084/jem.20100239

17. Lundberg K, Bengtsson C, Kharlamova N, Reed E, Jiang X, Kallberg H, et al. Genetic and environmental determinants for disease risk in subsets of rheumatoid arthritis defined by the anticitrullinated protein/peptide antibody fine specificity profile. Ann Rheum Dis. (2013) 72:652-8. doi: 10.1136/annrheumdis-2012-201484

18. Auger I, Sebbag M, Vincent C, Balandraud N, Guis S, Nogueira L, et al. Influence of HLA-DR genes on the production of rheumatoid arthritisspecific autoantibodies to citrullinated fibrinogen. Arthritis Rheum. (2005) 52:3424-32. doi: 10.1002/art.21391

19. Sokolove J, Bromberg R, Deane KD, Lahey LJ, Derber LA, Chandra $\mathrm{PE}$, et al. Autoantibody epitope spreading in the pre-clinical phase predicts progression to rheumatoid arthritis. PLoS ONE (2012) 7:e35296. doi: 10.1371/annotation/2e462817-ab93-4d78-95a4-1d8b9d172971

20. Willemze A, Bohringer S, Knevel R, Levarht EW, Stoeken-Rijsbergen G, Houwing-Duistermaat JJ, et al. The ACPA recognition profile and subgrouping of ACPA-positive RA patients. Ann Rheum Dis. (2012) 71:26874. doi: 10.1136/annrheumdis-2011-200421

21. Kinloch A, Tatzer V, Wait R, Peston D, Lundberg K, Donatien P, et al. Identification of citrullinated alpha-enolase as a candidate autoantigen in rheumatoid arthritis. Arthritis Res Ther. (2005) 7:R1421-9. doi: 10.1186/ar1845

22. Corsiero E, Bombardieri M, Carlotti E, Pratesi F, Robinson W, Migliorini $\mathrm{P}$, et al. Single cell cloning and recombinant monoclonal antibodies generation from RA synovial B cells reveal frequent targeting of citrullinated histones of NETs. Ann Rheum Dis. (2016) 75:1866-75. doi: 10.1136/annrheumdis-2015-208356

23. Tsuda R, Ozawa T, Kobayashi E, Hamana H, Taki H, Tobe K, et al. Monoclonal antibody against citrullinated peptides obtained from rheumatoid arthritis patients reacts with numerous citrullinated microbial and food proteins. Arthritis Rheumatol. (2015) 67:2020-31. doi: 10.1002/art.39161

24. Lu DR, McDavid AN, Kongpachith S, Lingampalli N, Glanville J, Ju CH, et al. $\mathrm{T}$ cell-dependent affinity maturation and innate immune pathways differentially drive autoreactive $\mathrm{B}$ cell responses in rheumatoid arthritis. Arthritis Rheumatol. (2018) 70:1732-44. doi: 10.1002/art.40578

25. Vergroesen RD, Slot LM, Hafkenscheid L, Koning MT, van der Voort EIH, Grooff CA, et al. B-cell receptor sequencing of anti-citrullinated protein antibody (ACPA) IgG-expressing B cells indicates a selective advantage for the introduction of $\mathrm{N}$-glycosylation sites during somatic hypermutation. Ann Rheum Dis. (2018) 77:956-8. doi: 10.1136/annrheumdis-2017-2 12052

26. Lloyd KA, Steen J, Amara K, Titcombe PJ, Israelsson L, Lundström SL, et al. Variable domain N-linked glycosylation and negative surface charge are key features of monoclonal ACPA: implications for B-cell selection. Eur J Immunol. (2018) 48:1030-45. doi: 10.1002/eji.201747446 
27. Rombouts Y, Willemze A, van Beers JJBC, Shi J, Kerkman PF, van Toorn $\mathrm{L}$, et al. Extensive glycosylation of ACPA-IgG variable domains modulates binding to citrullinated antigens in rheumatoid arthritis. Ann Rheum Dis. (2015) 75:578-85. doi: 10.1136/annrheumdis-2014-206598

28. Nielen MM, van Schaardenburg D, Reesink HW, van de Stadt RJ, van der Horst-Bruinsma IE, de Koning MH, et al. Specific autoantibodies precede the symptoms of rheumatoid arthritis: a study of serial measurements in blood donors. Arthritis Rheum. (2004) 50:380-6. doi: 10.1002/art.20018

29. Rantapaa-Dahlqvist S, de Jong BA, Berglin E, Hallmans G, Wadell G, Stenlund $\mathrm{H}$, et al. Antibodies against cyclic citrullinated peptide and IgA rheumatoid factor predict the development of rheumatoid arthritis. Arthritis Rheum. (2003) 48:2741-9. doi: 10.1002/art.11223

30. Brink M, Hansson M, Mathsson-Alm L, Wijayatunga P, Verheul MK, Trouw LA, et al. Rheumatoid factor isotypes in relation to antibodies against citrullinated peptides and carbamylated proteins before the onset of rheumatoid arthritis. Arthritis Res Ther. (2016) 18:43. doi: 10.1186/s13075-016-0940-2

31. Padyukov L, Silva C, Stolt P, Alfredsson L, Klareskog L. A gene-environment interaction between smoking and shared epitope genes in HLA-DR provides a high risk of seropositive rheumatoid arthritis. Arthritis Rheum. (2004) 50:3085-92. doi: 10.1002/art.20553

32. Arnett FC, Edworthy SM, Bloch DA, McShane DJ, Fries JF, Cooper NS, et al. The american rheumatism association 1987 revised criteria for the classification of rheumatoid arthritis. Arthritis Rheum. (1988) 31:315-24. doi: 10.1002/art.1780310302

33. Hansson M, Mathsson L, Schlederer T, Israelsson L, Matsson P, Nogueira L, et al. Validation of a multiplex chip-based assay for the detection of autoantibodies against citrullinated peptides. Arthritis Res Ther. (2012) 14:R201. doi: 10.1186/ar4039

34. Amara K, Clay E, Yeo L, Ramsköld D, Spengler J, Sippl N, et al. B cells expressing the IgA receptor FcRL4 participate in the autoimmune response in patients with rheumatoid arthritis. J Autoimmun. (2017) 81:34-43. doi: 10.1016/j.jaut.2017.03.004

35. Amara K, Steen J, Murray F, Morbach H, Fernandez-Rodriguez BM, Joshua V, et al. Monoclonal IgG antibodies generated from joint-derived B cells of RA patients have a strong bias toward citrullinated autoantigen recognition. J Exp Med. (2013) 210 445-55. doi: 10.1084/jem.20121486

36. Grönwall C, Amara K, Hardt U, Krishnamurthy A, Steen J, Engström M, et al. Autoreactivity to malondialdehyde-modifications in rheumatoid arthritis is linked to disease activity and synovial pathogenesis. J Autoimmun. (2017) 84:29-45. doi: 10.1016/j.jaut.2017.06.004

37. Tiller T, Meffre E, Yurasov S, Tsuiji M, Nussenzweig MC, Wardemann H. Efficient generation of monoclonal antibodies from single human B cells by single cell RT-PCR and expression vector cloning. J immunol methods (2008) 329:112-24. doi: 10.1016/j.jim.2007.09.017

38. Bournazos S, Klein F, Pietzsch J, Seaman MS, Nussenzweig MC, Ravetch JV. Broadly neutralizing anti-HIV-1 antibodies require Fc effector functions for in vivo activity. Cell (2014) 158:1243-53. doi: 10.1016/j.cell.2014.08.023

39. Skriner K, Hueber W, Suleymanoglu E, Hofler E, Krenn V, Smolen J, et al. AUF1, the regulator of tumor necrosis factor alpha messenger RNA decay, is targeted by autoantibodies of patients with systemic rheumatic diseases. Arthritis Rheum. (2008) 58:511-20. doi: 10.1002/art.23306

40. Grönwall C, Clancy RM, Getu L, Lloyd KA, Siegel DL, Reed JH, et al. Modulation of natural IgM autoantibodies to oxidative stress-related neo-epitopes on apoptotic cells in newborns of mothers with anti-ro autoimmunity. J Autoimmun. (2016) 73:30-41. doi: 10.1016/j.jaut.2016.05.014

41. Shevchenko A, Tomas H, Havlis J, Olsen JV, Mann M. In-gel digestion for mass spectrometric characterization of proteins and proteomes. Nat Protoc. (2006) 1:2856-60. doi: 10.1038/nprot.2006.468

42. Cox J, Mann M. MaxQuant enables high peptide identification rates, individualized p.p.b.-range mass accuracies and proteome-wide protein quantification. Nat Biotechnol. (2008) 26:1367-72. doi: 10.1038/nbt.1511

43. Mullazehi M, Mathsson L, Lampa J, Ronnelid J. Surface-bound anti-type II collagen-containing immune complexes induce production of tumor necrosis factor alpha, interleukin-1beta, and interleukin-8 from peripheral blood monocytes via Fc gamma receptor IIA: a potential pathophysiologic mechanism for humoral anti-type II collagen immunity in arthritis. Arthritis Rheum. (2006) 54:1759-71. doi: 10.1002/art.21892
44. Chan EK, Damoiseaux J, Carballo OG, Conrad K, de Melo Cruvinel W, Francescantonio PL, et al. Report of the first international consensus on standardized nomenclature of antinuclear antibody HEp-2 cell patterns 20142015. Front Immunol. (2015) 6:412. doi: 10.3389/fimmu.2015.00412

45. Andrade F, Darrah E, Gucek M, Cole RN, Rosen A, Zhu X. Autocitrullination of human peptidyl arginine deiminase type 4 regulates protein citrullination during cell activation. Arthritis Rheum. (2010) 62:1630-40. doi: $10.1002 /$ art.27439

46. Sykes DB, Kamps MP. Estrogen-dependent E2a/Pbx1 myeloid cell lines exhibit conditional differentiation that can be arrested by other leukemic oncoproteins. Blood (2001) 98:2308-18. doi: 10.1182/blood.V98.8.2308

47. Panda SK, Boddul SV, Jimenez-Andrade GY, Jiang L, Kasza Z, FernandezRicaud L, et al. Green listed-a CRISPR screen tool. Bioinformatics (2017) 33:1099-100. doi: 10.1093/bioinformatics/btw739

48. Doench JG, Fusi N, Sullender M, Hegde M, Vaimberg EW, Donovan KF, et al. Optimized sgRNA design to maximize activity and minimize off-target effects of CRISPR-Cas9. Nat Biotechnol. (2016) 34:184-91. doi: 10.1038/nbt.3437

49. Ran FA, Hsu PD, Wright J, Agarwala V, Scott DA, Zhang F. Genome engineering using the CRISPR-Cas9 system. Nat Protoc. (2013) 8:2281-308. doi: 10.1038/nprot.2013.143

50. Wermeling F, Lind SM, Jordo ED, Cardell SL, Karlsson MC. Invariant NKT cells limit activation of autoreactive CD1d-positive B cells. J Exp Med. (2010) 207:943-52. doi: 10.1084/jem.20091314

51. Agmon-Levin N, Damoiseaux J, Kallenberg C, Sack U, Witte T, Herold M, et al. International recommendations for the assessment of autoantibodies to cellular antigens referred to as anti-nuclear antibodies. Ann Rheum Dis. (2014) 73:17-23. doi: 10.1136/annrheumdis-2013-203863

52. Duhlin A, Chen Y, Wermeling F, Sedimbi SK, Lindh E, Shinde R, et al. Selective memory to apoptotic cell-derived self-antigens with implications for systemic lupus erythematosus development. J Immunol. (2016) 197:2618-26. doi: 10.4049/jimmunol.1401129

53. Mevorach D, Zhou JL, Song X, Elkon KB. Systemic exposure to irradiated apoptotic cells induces autoantibody production. J Exp Med. (1998) 188:38792. doi: $10.1084 / \mathrm{jem} .188 .2 .387$

54. Liu Y, Lightfoot Y, Set N, Carmona-Rivera C, Moore E, O'Neil L, et al. Peptidylarginine deiminases 2 and 4 modulate innate and adaptive immune responses in TLR7-dependent lupus. JCI Insight (2018) 3:e124729. doi: $10.1172 /$ jci.insight.124729

55. Kuhn KA, Kulik L, Tomooka B, Braschler KJ, Arend WP, Robinson WH, et al. Antibodies against citrullinated proteins enhance tissue injury in experimental autoimmune arthritis. J Clin Invest. (2006) 116:961-73. doi: 10.1172/JCI25422

56. Sohrabian A, Mathsson-Alm L, Hansson M, Knight A, Lysholm J, Cornillet $\mathrm{M}$, et al. Number of individual ACPA reactivities in synovial fluid immune complexes, but not serum anti-CCP2 levels, associate with inflammation and joint destruction in rheumatoid arthritis. Ann Rheum Dis. (2018) 77:1345-53. doi: 10.1136/annrheumdis-2017-212627

57. Romero V, Fert-Bober J, Nigrovic PA, Darrah E, Haque UJ, Lee DM, et al. Immune-mediated pore-forming pathways induce cellular hypercitrullination and generate citrullinated autoantigens in rheumatoid arthritis. Sci Transl Med. (2013) 5:209ra150. doi: 10.1126/scitranslmed.3006869

58. Wardemann H, Yurasov S, Schaefer A, Young JW, Meffre E, Nussenzweig MC. Predominant autoantibody production by early human B cell precursors. Science (2003) 301:1374-7. doi: 10.1126/science.1086907

59. Grönwall C, Vas J, Silverman GJ. Protective roles of natural IgM antibodies. Front Immunol. (2012) 3:66. doi: 10.3389/fimmu.2012.00066

60. Sigurdsson S, Padyukov L, Kurreeman FA, Liljedahl U, Wiman AC, Alfredsson $\mathrm{L}$, et al. Association of a haplotype in the promoter region of the interferon regulatory factor 5 gene with rheumatoid arthritis. Arthritis Rheum. (2007) 56:2202-10. doi: 10.1002/art.22704

61. Radic MZ, Weigert M. Genetic and structural evidence for antigen selection of anti-DNA antibodies. Annu Rev Immunol. (1994) 12:487-520. doi: 10.1146/annurev.iy.12.040194.002415

62. Losman JA, Fasy TM, Novick KE, Massa M, Monestier M. Nucleosomespecific antibody from an autoimmune MRL/Mp-lpr/lpr mouse. Arthritis Rheum. (1993) 36:552-60. doi: 10.1002/art.1780360417

63. Harr MW, Distelhorst CW. Apoptosis and autophagy: decoding calcium signals that mediate life or death. Cold Spring Harb Perspect Biol. (2010) 2:a005579. doi: 10.1101/cshperspect.a005579 
64. Neeli I, Khan SN, Radic M. Histone deimination as a response to inflammatory stimuli in neutrophils. J Immunol. (2008) 180:1895-902. doi: 10.4049/jimmunol.180.3.1895

65. Wu D, Ingram A, Lahti JH, Mazza B, Grenet J, Kapoor A, et al. Apoptotic release of histones from nucleosomes. J Biol Chem. (2002) 277:12001-8. doi: 10.1074/jbc.M109219200

66. Radic M, Marion T, Monestier M. Nucleosomes are exposed at the cell surface in apoptosis. J Immunol. (2004) 172:6692-700. doi: 10.4049/jimmunol.172.11.6692

67. Asaga H, Yamada M, Senshu T. Selective deimination of vimentin in calcium ionophore-induced apoptosis of mouse peritoneal macrophages. Biochem Biophys Res Commun. (1998) 243:641-6. doi: 10.1006/bbrc.1998.8148

68. Fullgrabe J, Hajji N, Joseph B. Cracking the death code: apoptosisrelated histone modifications. Cell Death Differ. (2010) 17:1238-43. doi: $10.1038 /$ cdd. 2010.58

69. Juarez M, Bang H, Hammar F, Reimer U, Dyke B, Sahbudin I, et al. Identification of novel antiacetylated vimentin antibodies in patients with early inflammatory arthritis. Ann Rheum Dis. (2016) 75:1099-107. doi: 10.1136/annrheumdis-2014-206785

70. Figueiredo CP, Bang H, Cobra JF, Englbrecht M, Hueber AJ, Haschka J, et al. Antimodified protein antibody response pattern influences the risk for disease relapse in patients with rheumatoid arthritis tapering disease modifying antirheumatic drugs. Ann Rheum Dis. (2017) 76:399-407. doi: 10.1136/annrheumdis-2016-209297

71. Rohrbach AS, Slade DJ, Thompson PR, Mowen KA. Activation of PAD4 in NET formation. Front Immunol. (2012) 3:360. doi: 10.3389/fimmu.2012.00360

72. Lewis HD, Liddle J, Coote JE, Atkinson SJ, Barker MD, Bax BD, et al. Inhibition of PAD4 activity is sufficient to disrupt mouse and human NET formation. Nat Chem Biol. (2015) 11:189-91. doi: 10.1038/nchembio.1735

73. Pratesi F, Dioni I, Tommasi C, Alcaro MC, Paolini I, Barbetti F, et al. Antibodies from patients with rheumatoid arthritis target citrullinated histone 4 contained in neutrophils extracellular traps. Ann Rheum Dis. (2014) 73:1414-22. doi: 10.1136/annrheumdis-2012-202765
74. Pieterse E, Hofstra J, Berden J, Herrmann M, Dieker J, van der Vlag J. Acetylated histones contribute to the immunostimulatory potential of neutrophil extracellular traps in systemic lupus erythematosus. Clin Exp Immunol. (2015) 179:68-74. doi: 10.1111/cei.12359

75. Dieker JW, Fransen JH, van Bavel CC, Briand JP, Jacobs CW, Muller S, et al. Apoptosis-induced acetylation of histones is pathogenic in systemic lupus erythematosus. Arthritis Rheum. (2007) 56:1921-33. doi: 10.1002/art. 22646

76. Dieker J, Berden JH, Bakker M, Briand JP, Muller S, Voll R, et al. Autoantibodies against modified histone peptides in SLE patients are associated with disease activity and lupus nephritis. PLOS ONE (2016) 11:e0165373. doi: 10.1371/journal.pone.0165373

77. Konig MF, Andrade F. A critical reappraisal of neutrophil extracellular traps and NETosis mimics based on differential requirements for protein citrullination. Front Immunol. (2016) 7:461. doi: 10.3389/fimmu.2016.00461

78. van de Stadt LA, van Schouwenburg PA, Bryde S, Kruithof S, van Schaardenburg D, Hamann D, et al. Monoclonal anti-citrullinated protein antibodies selected on citrullinated fibrinogen have distinct targets with different cross-reactivity patterns. Rheumatology (2013) 52:631-5. doi: 10.1093/rheumatology/kes371

Conflict of Interest Statement: The authors declare that the research was conducted in the absence of any commercial or financial relationships that could be construed as a potential conflict of interest.

Copyright (c) 2019 Lloyd, Wigerblad, Sahlström, Garimella, Chemin, Steen, Titcombe, Marklein, Zhou, Stålesen, Ossipova, Lundqvist, Ekwall, Rönnelid, Mueller, Karlsson, Kaplan, Skriner, Klareskog, Wermeling, Malmström and Grönwall. This is an openaccess article distributed under the terms of the Creative Commons Attribution License (CC BY). The use, distribution or reproduction in other forums is permitted, provided the original author(s) and the copyright owner(s) are credited and that the original publication in this journal is cited, in accordance with accepted academic practice. No use, distribution or reproduction is permitted which does not comply with these terms. 